\title{
Wage Rigidity and Disinflation in Emerging Countries
}

\author{
By Julián Messina and Anna SAnZ-DE-GaldeAno*
}

\begin{abstract}
This paper examines the consequences of rapid disinflation for downward wage rigidities in two emerging countries, Brazil and Uruguay. Although wage rigidities are altered by disinflation, in neither of the two countries does price stability eliminate frictions in wage-setting mechanisms. In a context of individual wage negotiations and weak unions, disinflation in Uruguay puts an end to its history of indexation, but strong resistance to nominal wage cuts emerges. In strongly unionized Brazil, wage indexation is highly persistent, but the introduction of inflation targeting by the Central Bank in 1999 moves the focal point of wage negotiations to expected inflation. (JEL E31, E52, J31, J51, O11, O15, O23)
\end{abstract}

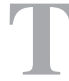
he incidence and nature of downward wage rigidities vary markedly across countries. In the United States, an ample literature suggests that workers resist nominal wage cuts (e.g., Kahn 1997; Altonji and Devereux 2000; Lebow, Saks, and Wilson 2003). In contrast, downward nominal wage rigidity (DNWR) is lower in Europe, where downward real wage rigidities (DRWRs), introduced through different forms of explicit or implicit indexation of wages to prices, appear to be more relevant. Institutional settings, and in particular unions and firing restrictions, have been argued to explain such differences (Dickens et al. 2007; Holden and Wulfsberg 2008, 2009).

Notwithstanding cross-country heterogeneity, changes in the rigidity regime within countries are seldom observed. Goette, Bauer, and Sunde (2007) show that workers' resistance to nominal wage cuts remains persistently high in Switzerland in spite of a prolonged period of very low inflation and GDP growth. Barwell and Schweitzer (2007) in the United Kingdom, Bauer et al. (2007) in Germany, and Devicienti, Maida, and Sestito (2007) in Italy show that real rigidities are more

\footnotetext{
* Messina: World Bank, Office of the Chief Economist for Latin America and the Caribbean Region at the World Bank. 1818 H St., NW, Washington, DC 20433, and Universitat de Girona and Institute for the Study of Labor (IZA) (e-mail: jmessina@worldbank.org); Sanz-de-Galdeano: Center for Research in Health and Economics (CRES-UPF), Mercè Rodoreda Building, Ramon Trias Fargas, 25-27, 08005, Barcelona, Spain, and World Bank and IZA (e-mail: anna.sanzdegaldeano@gmail.com). This research was sponsored by the World Bank under contract number 7793093. The opinions expressed in this article do not necessarily reflect the views of the World Bank. The authors declare that they have no relevant or material financial interests that relate to the research described in this paper. We are grateful to three anonymous referees, Francesco Devicienti, Chico Ferreira, Stefano Gnocchi, Lorenz Goette, Gustavo Gonzaga, Steinar Holden, Alain Ize, Evi Pappa, Marcelo Soto, Augusto de la Torre, Carlos Vegh, and seminar participants at the World Bank, Inter-American Development Bank, PUC-Rio, University de la Plata, University di Tella, IAE-UAB, and LUISS Guido Carli for helpful comments on earlier drafts. We are especially grateful to Álvaro Forteza and Ianina Rossi for their help with the data from Uruguay. Manuel Fernández-Sierra provided invaluable research assistance. Financial support from the Government of Catalonia (contract no. 2009SGR189 and the XREPP) and the Government of Spain (through the SFLAC TF and ECO2011-28822 Grant) is gratefully acknowledged.

Go to http://dx.doi.org/10.1257/mac.6.1.102 to visit the article page for additional materials and author disclosure statement(s) or to comment in the online discussion forum.
} 
important than workers' resistance to nominal wage cuts through a period of almost two decades. A possible rationale for the persistence in wage rigidities across countries is that the macro and policy environment in the countries and periods previously studied were relatively stable, offering little variation to identify the impacts on wage setting of macro and policy changes.

This paper contributes to the understanding of the nature and incidence of downward wage rigidities in environments characterized by sharp macroeconomic and policy changes. First, there is no information regarding how wagesetting regimes respond to rapid disinflation periods. In a high-inflation regime, wage indexation is likely to be pervasive. In contrast, DNWR is likely to be irrelevant. To the extent that such indexation is persistent, disinflation policies are much harder to obtain. Is indexation rapidly easing as disinflation policies are introduced? Does this weakening of indexation lead the way to flexible wage setting, or do DNWRs arise? We shed some new light on these questions and assess the role of the institutional environment in shaping the response of wage setters to the disinflation process.

Second, to our knowledge, we are the first to document empirically how a change in the monetary policy regime - the introduction of inflation targetingalters the nature of wage rigidity. A rationale for inflation targeting is to move the economy from high-inflation equilibria to low-inflation equilibria by providing a focal point to economic agents. As Bernanke (2004) suggested, explicit or implicit indexation clauses should ultimately depend on the monetary policy regime. However, little is known about the response of wage setters to such institutional changes.

To analyze these issues, we examine the evolution of wage rigidities in two emerging countries, Brazil and Uruguay, that have experienced rapid disinflation and institutional changes. Brazil and Uruguay successfully reduced inflation after the introduction of stabilization policies in the 1990s-moving from three-digit levels (four, in Brazil) in the first years of the stabilization effort to one-digit levels by the end of the decade (see Figure 1). Our analysis begins in the transition years: 1995 in Brazil and 1996 in Uruguay.

The contrast of the two countries is informative because, during this period, their labor market institutions differed sharply. We focus on two institutions that are likely to be of particular relevance for wage rigidities. The first one, the structure of the wage-bargaining system and the role of unions, has been stressed as a key source of downward wage rigidities in the empirical literature that focuses on high-income countries. The second one, the minimum wage, may be of more relevance for lowand middle-income countries. In Uruguay, the government policy of dismantling the Consejo de Salarios, a tripartite system of wage bargaining, led to decentralized wage-setting whereby unions lost a great deal of bargaining power (SenatoreCamerota 2007). In contrast, union coverage in Brazil remained fairly high and stable, with sectoral bargaining featuring automatic extension clauses that prevailed as the most common wage-bargaining regime in the formal sector (Arbache 2002). Minimum wages in Uruguay are among the lowest in Latin America, whereas in Brazil they are much closer to the median wage. To the extent that changes in the minimum wage constitute a signal for wage bargaining across all sectors (Maloney 


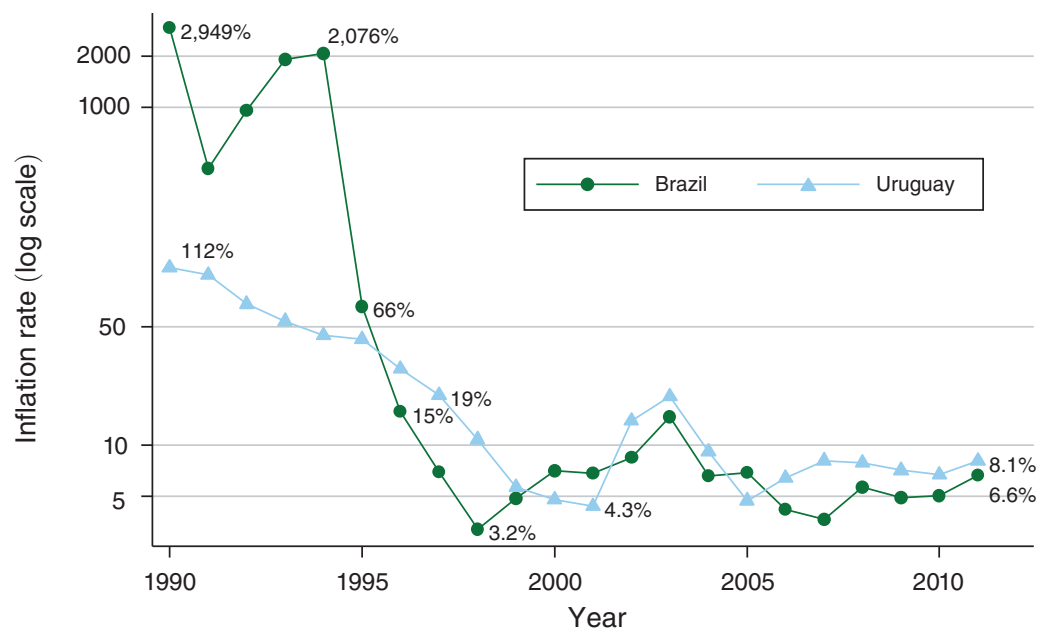

Figure 1. The Evolution of Inflation in Brazil and Uruguay, 1990-2011

and Mendez 2004), they might be an important source of de facto indexation in Brazil. 1

We rely on fairly rich matched employer-employee data from administrative records in Brazil and Uruguay, which allow us to obtain accurate measures of hourly wages and to properly track worker mobility. The analysis is carried out using the maximum likelihood estimator first proposed by Altonji and Devereux (2000) and extended to consider DRWR by Goette, Bauer, and Sunde (2007). Goette, Bauer, and Sunde (2007) model wage changes as a function of individual and firm characteristics to build a counterfactual or notional distribution, which is the distribution that would have prevailed in the absence of wage rigidities.

In the model, the likelihood of each individual wage change observation belongs to one of three wage-setting regimes: (i) flexible wages, in which case the actual wage change coincides with the notional wage change; (ii) DNWR, which implies that if the individual is scheduled for a wage cut, she instead receives a wage freeze; and (iii) DRWR, where if the individual is scheduled for a wage change that fell below a threshold $r_{i}>0$, she instead receives a wage change equal to this minimum acceptable threshold. Importantly, this threshold that determines the focal point of DRWR in wage negotiations is endogenously determined by the model and is allowed to be heterogeneous across workers. This permits ex post evaluation of the relationship between this price index and different prices in the economy, which is crucial for understanding the sources of indexation. The model also allows for errors in the measurement of wages. This is potentially important because measurement

\footnotetext{
${ }^{1}$ For instance, Castellanos, García-Verdú, and Kaplan (2004) study downward wage rigidity in Mexico and find clear signs of indexation to the minimum wage. Our paper differs from this study in three respects. First, we allow for the presence of measurement errors in the estimation, an aspect that has received considerable attention in the literature in the recent years. Second, we do not impose wage indexation to follow a predetermined price index. Instead, the price index considered in wage negotiations is allowed to be heterogeneous across agents and is endogenously determined. Finally, our model is estimated year by year to track changes in the distribution of wage changes over time.
} 
error in wage data has been shown to be a source of downward bias in the estimated incidence of DNWR (Gottschalk 2005).

Our results indicate that Brazil and Uruguay present substantial differences in the nature of wage rigidities and in their reaction to changes in the macroeconomic and institutional environments. In the private formal sector of Uruguay, the pegging of individual nominal wage growth to the rate of inflation falls dramatically as inflation stabilizes at lower levels. DRWR affects, on average, 75 percent of the workforce in the period 1996-1999, decreasing to a fairly stable 7 percent for the rest of the sample period (1999-2004). In parallel, the fraction of workers subject to DNWR increases from around 13 percent in the first three years to an average of 66 percent in the second part of the sample. Hence, disinflation is associated with a sharp movement away from wage indexation. However, this process does not lead the way to a frictionless wage-setting regime. Instead, worker resistance to nominal wage cuts arises. Interestingly, these changes appear to constitute a genuine regime shift. When inflation peaks again in Uruguay during the years 2002-2004, wage indexation does not return, and DNWR remains as the fundamental wage-setting friction.

In contrast with Uruguay, the share of workers subject to wage indexation in Brazil is fairly high and stable, affecting on average 43 percent of the workforce. There is, however, an important regime shift in Brazil, and this shift is related to the focal point of DRWR, or the price index to which nominal wages are indexed. During the first years of the sample, up to 1999, the focal point of wage negotiations is tightly linked to the change in the minimum wage. After the introduction of inflation targeting in 1999, this focal point moves away from the minimum wage and becomes closely related to the evolution of inflation, a feature that is consistent with the anchoring of inflation expectations by the new monetary policy regime. Interestingly, the variance across agents of the focal point in wage negotiations also increases after 1999 — a feature that is consistent with the index being an indicator of inflation expectations.

The results in this paper are related to two recent macro studies. In the context of price setting, Benati (2008) shows that the rate of inflation persistence in different countries and time periods varies with the monetary policy regime. Similar evidence is presented by Hofmann, Peersman, and Straub (2010) in the context of US wage dynamics. Our work is a first attempt to examine the stability of downward nominal and real wage rigidities in an environment subject to policy changes and rapid macroeconomic stabilization. To achieve this goal, relying on micro data is fundamental. An economy can display substantial wage rigidity within ongoing employment relationships and, at the same time, present fairly flexible wages at the macro level if wage flexibility at the margin is obtained through labor market turnover. This seems to be the case in Brazil. We finish the discussion with an analysis of median wage changes in sectors and occupations. The macro wage change distributions of either formal or informal sectors show no signs of wage rigidities, even in those years where we find substantial wage indexation at the micro level.

The rest of the paper is organized as follows. Section I describes the datasets used and presents wage change histograms for selected years, discussing their main features and why they are suggestive of different types of rigidities. Section II 
discusses the methodology used to deal with measurement errors and the joint estimation of the different types of rigidity. Section III presents the main results of the paper, and Section IV presents robustness checks of the baseline model. In Section V, we extend the analysis of the incidence of wage rigidities to sectors and occupations rather than individual wages. Section VI concludes.

\section{Data}

\section{A. Data Sources and Sample Selection}

We use annual administrative employer-employee matched data from Brazil (1995-2002) and Uruguay (1996-2004). The main difference between the two datasets is that while the former is comprehensive, including information for the universe of workers in the formal sector in the state of Minas Gerais (Brazil), the latter provides us with information on a random sample of workers in Uruguay's formal sector.

Our data source for Brazil is the labor market census, Relação Annual de Informações Sociais (RAIS), an administrative dataset collected annually by the Brazilian Labor Ministry. By Brazilian law, all employers in the formal sector must report detailed information for all their workers to RAIS every year. RAIS includes information about workers (gender, age, education) and their jobs (type of contract, occupation, average monthly wage earned during the year, wage earned in December, and the amount of hours usually worked per week), as well as some characteristics of the establishment (sector, region, municipality). Importantly, RAIS also provides firm, establishment, and worker identifiers, which, together with the dates of admission and separation, allow us to accurately identify year-to-year job stayers.

Our Uruguayan data consist of social security records from the Banco de Previsión Social (BPS). After the 1995 social security reform, the BPS started keeping employer and employee administrative records on a monthly basis. We exploit a random sample of the BPS records, which, like those of the Brazilian RAIS, contain information on establishments (number of employees, sector, region), workers (age, gender), and their jobs (occupation, weekly hours of work, monthly wages). Establishments and workers are uniquely tracked by an individual identifier and an establishment identifier. Each job within a worker-establishment pair is uniquely identified as well, which allows us to track year-to-year job stayers who have been neither promoted nor demoted. This job identifier, however, is not available in RAIS, so for the sake of comparability in our empirical analysis we define stayers as workers who are continuously employed in the same establishment for a year or more. ${ }^{2}$

Regarding the compensation measures used in our analysis, RAIS reports monthly wages earned in December, which include extraordinary additions, supplements and bonuses, tips and gratuities, commissions and fees, contracted premia, overtime compensation for contracted extra hours, and, in general, all forms of payment that are taxable income or are subject to Brazilian social security contributions. The "13th salary,'the special December payment that is made in some sectors, as well as severance

\footnotetext{
${ }^{2}$ However, it is worth noting that our results are very similar when we exclude promoted or demoted employees from our Uruguayan sample of stayers.
} 
payments for layoffs and indemnity payments are not considered wage components. Therefore, we construct a comparable monthly wage measure from Uruguay's BPS that excludes severance payments and the special December payment. The number of hours worked per week is reported in both datasets. There are some differences, though, in the way hours are measured in each dataset. The RAIS data report contractual hours, while BPS records actual hours worked during the week of reference.

Hourly wages in each dataset are constructed using the compensation and hours worked in that dataset. Note that none of our measures of hourly wages is, in principle, exempted from measurement errors. Since individuals' working-time arrangements are not time-invariant, even if they stay in the same job, some of the observed monthly wage changes will actually reflect changes in labor input. Computing hourly wages from RAIS will only partially mitigate this problem as long as changes in hours are reflected in the contract. The hourly wage measure in Uruguay might be more accurate, but variations in weekly hours of work throughout the month will result in measurement errors. In sum, even if our two data sources are less likely to be subject to measurement error than survey data, we cannot rule out the possibility of measurement error. Hence, the model described in Section II allows for the presence of measurement error in the estimation.

In Section IV, we exploit a third data source, the Brazilian annual household survey or Pesquisa Nacional por Amostra de Domicilios (PNAD), to analyze wage changes at the occupational level. $]^{3}$ The PNAD contains 340 occupational categories, on average, up to 2002. The occupational classification changes in 2002, increasing the total number of occupations to 438 . Note that the survey was not carried out in 2000 . This fact, together with the methodological change of 2002, implies that we cannot calculate wage changes for the period 1999-2002. We limit the sample to the period 1995-2004.

We apply the same sample selection criteria to the three data sources. First, we restrict our sample to full-time employees aged 14-65 working in the private sector. Second, whenever individuals have more than one job, we always keep the observation with the highest paying job. Our benchmark analysis of individual wage growth using RAIS and BPS, which we define as the difference in log wages over a 12-month interval, is limited to job stayers, who are characterized by working in the same establishment in the same month in two adjacent years. These data restrictions leave 7 years of wage change observations in Brazil (containing between 857,589 and 1,200,120 individual cases) and 8 years in Uruguay (including between 68,494 and 97,721 individual wage changes).

Before moving forward, two potential data limitations should be discussed. First, we had no access to the full RAIS sample but only to the universe of formal workers in the state of Minas Gerais. This may be a limitation if the labor market in Minas Gerais is not representative of the whole country. To assess the representativeness of the Minas Gerais labor market, we have compared the socioeconomic characteristics of Minas Gerais with the rest of the country using the PNAD and found that differences in age, gender, years of schooling, the sectoral structure of the economy, and

\footnotetext{
${ }^{3}$ The Brazilian occupational classification system, the Classificação Brasileira de Ocupações (CBO), is profession-based, hence, it combines elements related to the skills needed for the job with the sectoral affiliation of the job. For simplicity, throughout the paper we refer to these profession-based occupations simply as occupations.
} 
main labor market aggregates (e.g., employment, unemployment, and informality) are marginal. We have also compared wage change distributions where the unit of observation is the median wage in detailed occupations using data from the PNAD for all years in the sample. We found that, with the exception of the first two years when wage changes in the state of Minas Gerais present fatter tails, the wage change distributions are remarkably similar. The evidence thus suggests that the labor market in Minas Gerais is likely to be well suited to represent the Brazilian labor market. ${ }^{4}$

A second aspect that requires some discussion regards the fact that the administrative sources examined in this study cover only the formal sector of the economy. To the extent that the distribution of wage changes in formal and informal sectors is substantially different, this may be an important concern, especially in Brazil, where informal employment is much higher (39 percent of the total number of employees, on average) than in Uruguay. ${ }^{5,6}$ To shed some light on this issue, we return to the PNAD and contrast the distribution of occupational wage changes among formal and informal workers considered separately (Figure 2). Interestingly, the two distributions present a very similar shape. Both distributions are skewed to the right, and there is not a clear pattern of statistical dominance; in some years (e.g., 1995-1997 and 1998-1999) the right tail of wage changes of informal workers weakly dominates that of formal employees, while in others (1996-1997 and 1997-1998) the opposite pattern prevails. These differences, moreover, are fairly small. While this evidence does not rule out the possibility that the distribution of wage changes of stayers (the focus of our analysis) may differ between informal and formal sectors, it is suggestive that such differences may not be too large.

\section{B. Descriptive Evidence}

To get an initial impression of the different types of rigidities that prevail under different inflation scenarios, in this section, we look at individual wage change distributions from selected years (Figures 3 and 4). In line with our previous discussion, we concentrate on the yearly nominal log-wage change distribution of private sector workers staying in the same job for two consecutive years. Each bin contains a 1 percent variation in wages, and we have restricted nominal wage changes to be below 40 percent and above -10 percent in the figures to highlight the distortions associated with DNWR and indexation. Two vertical lines are also shown in the graph. The solid line is the yearly inflation rate, while the dashed line shows the yearly growth rate of the minimum wage.

We start by discussing the earlier period in our sample, when inflation had already started coming down but was still at double-digit levels. Panel A of Figure 3 shows the wage change histogram in 1997-1998 in Uruguay. This is the first year

\footnotetext{
${ }^{4}$ See the online Appendix for tables and figures comparing Minas Gerais with the rest of Brazil.

${ }^{5}$ Uruguay is the Latin American country with the lowest rate of informality. According to the National Household Survey (Encuesta Nacional de Hogares Ampliada), the share of informal employment (defined as those employees not registered with social security) in 2001 accounted for 22 percent of the total number of employees.

${ }^{6}$ We define informal employees in Brazil as those without a labor ID card, or carteira. This ID card provides workers with access to employment protection and other social benefits. This definition is equivalent to our definition for Uruguay and is the most widely used in the case of Brazil (see, for instance, Perry et al. 2007).
} 

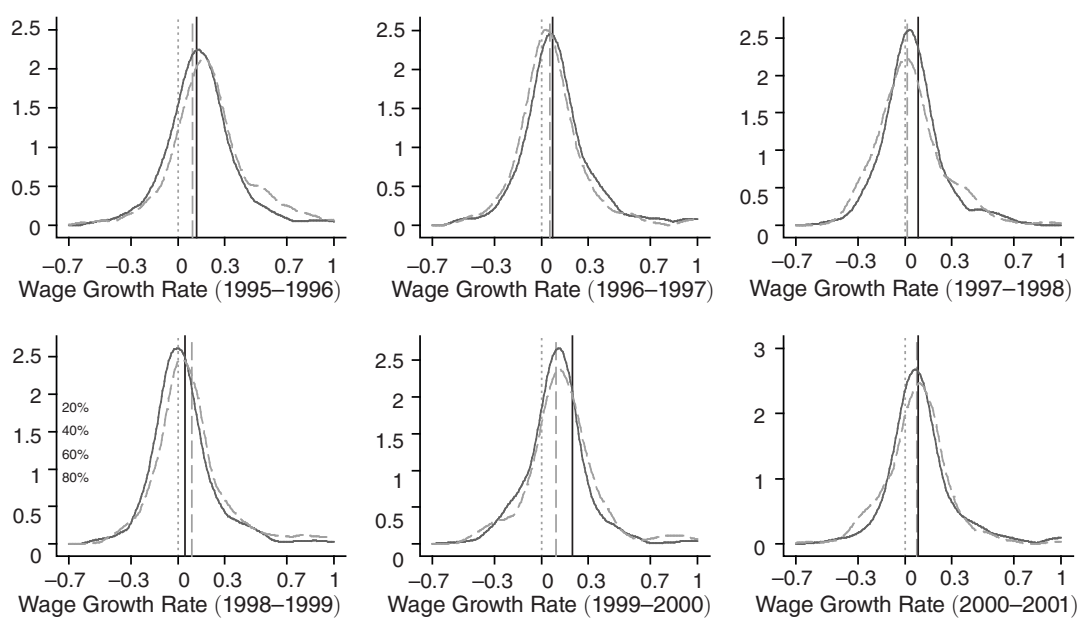

Formal $-\ldots-$ Informal

Figure 2. Annual Median Wage Growth Distributions,

FORMAL VERSUS INFORMAL EMPLOYEES

Notes: Dotted line: zero growth rate in nominal wages. Dashed line: inflation rate. Solid line: minimum wage growth. Formal employees are those who have an ID card or carteira.

of moderate (10.81 percent) inflation after the introduction of the stabilization plan in 1990. The first notable aspect is a concentration of observations at zero wage changes (around 7 percent), and the relatively small mass below it, in what seems to be a sign of DNWR. There is another important asymmetry in the distribution. A large mass of observations is clustered right below the inflation rate, in the 9 percent bin, while the percentage of workers with wage changes right below this bin is clearly lower than the percentage of wage changes above it. Naturally, economic agents do not necessarily have the same expectations about inflation or the same reference value in wage negotiations. Hence, the distortion associated with indexation clauses cannot be seen as clearly in the histograms as the concentration of observations at zero wage changes. In this case, for instance, the distortion is not at the rate of inflation but right below it. However, the cluster of observations around the rate of inflation might be a sign of partial indexation clauses. This will be taken into account in the empirical analysis by allowing for inflation expectations or the focal point in wage negotiations to differ across agents. Finally, note also that the growth of the minimum wage lies well above the rate of inflation, and there are no signs of distortion in this part of the distribution. As we will see, this is in sharp contrast with what is happening in Brazil during this period.

Panel B of Figure 3 shows the wage change histogram in 1995-1996 in Brazil. This is right after the introduction of the stabilization plan in 1994, the Plano Real (Real Plan), which succeeded in sharply bringing down inflation from 2,075 percent in 1993-1994 to 15.75 percent in 1995-1996. The first noticeable aspect is a large spike in the 12 percent bin, which accounts for some 15 percent of the wage change observations and more than triples the mass in the adjacent bins. The 12 percent bin coincides with the growth of the minimum wage (11.99 percent), which forcefully 
Panel A. Uruguay 1997-1998

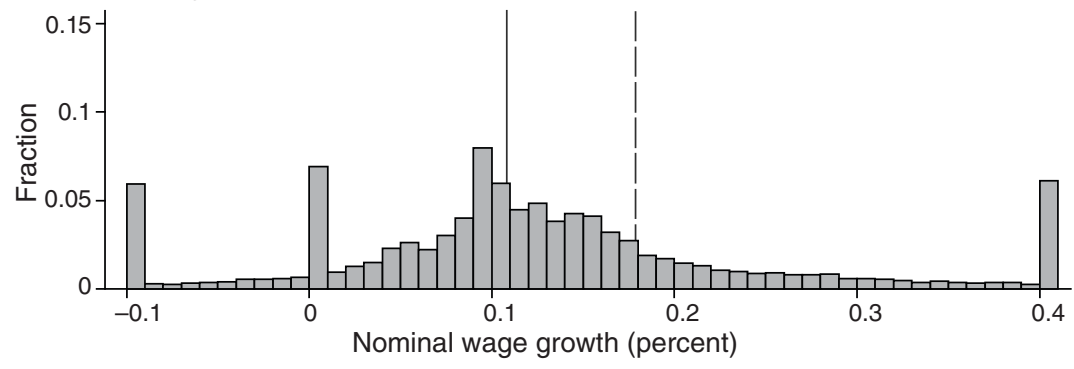

Panel B. Brazil 1995-1996

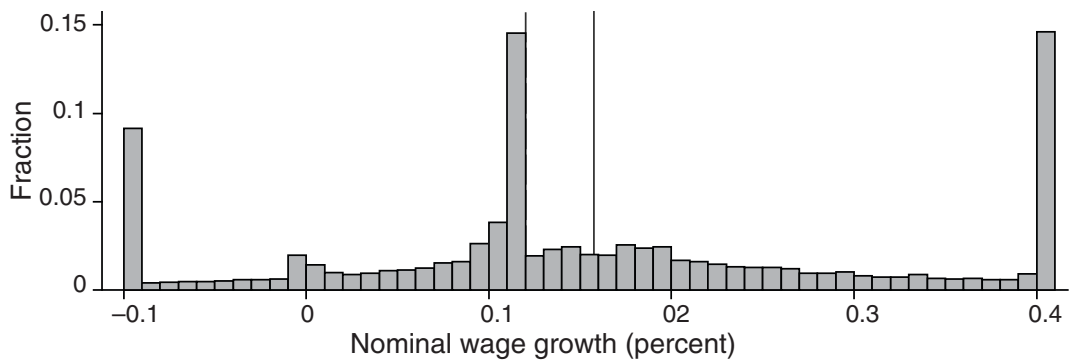

Figure 3. Histograms of Observed Log Hourly Wage Changes, Double-Digit Inflation Years

Notes: Solid line: inflation rate. Dashed line: minimum wage growth. The first (last) bin in each histogram corresponds to the frequency of all the observations with an annual growth below (above) $-0.1(0.4)$.
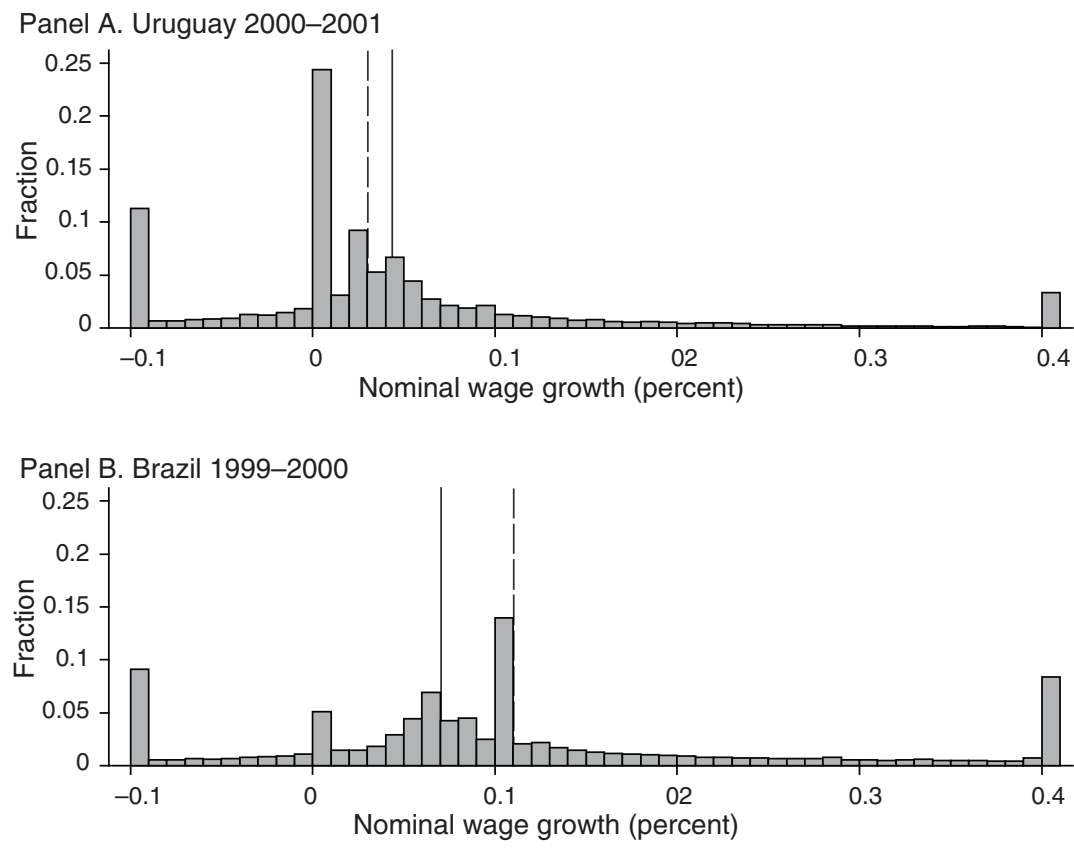

Figure 4. Histograms of Observed Log Hourly Wage Changes, Single-Digit Inflation Years

Notes: Solid line: inflation rate. Dashed line: minimum wage growth. The first (last) bin in each histogram corresponds to the frequency of all the observations with an annual growth below (above) $-0.1(0.4)$. 
suggests that the price index used to index wage contracts this year is the change in the minimum wage. Note also that there are no distortions associated with the rate of inflation. Quite surprisingly, we find very few zero wage changes, but the -1 percent bin shows a small spike. This concentration of tiny wage cuts is suggestive of measurement error.

We move next to the low-inflation years. Panel A of Figure 4 shows the wage change distribution in Uruguay in 2000-2001, when inflation is at its low for the period ( 4.35 percent). The most striking feature with respect to the high-inflation year is the growth in the spike at zero, which now accounts for almost 25 percent of the wage change observations. As before, there is some concentration of observations around the rate of inflation, but to a much lesser extent than in 1997-1998. Panel B of Figure 4 shows the 1999-2000 histogram in Brazil. As before, the change in the minimum wage is associated with a large spike, amounting to 14 percent of the wage changes. The novelty is that there appears to be a second distortion in the positive wage change range, this time associated with the rate of inflation. This could indicate that, as inflation comes down, some agents start indexing their wages to expected or past inflation as opposed to changes in the minimum wage.

In sum, visual inspection of the wage change histograms suggests an important presence of downward rigidities and indexation in both countries in all years. However, obtaining precise measures of downward wage rigidities is complicated because of the presence of measurement error in the data and the existence of different focal points for wage indexation. The next section presents a model that deals with these two features and provides us with clean measures of DNWR and the extent of wage indexation.

\section{Methodology}

The econometric model we employ builds on the work first proposed by Altonji and Devereux (2000), who develop a wage-setting model in which the parameters that govern DNWR and measurement errors are jointly estimated via maximum likelihood. This methodology has been extended by Goette, Bauer, and Sunde (2007) to consider DRWR, or the resistance of nominal wages to fall below an estimated positive threshold, and has been applied to case studies in the United Kingdom (Barwell and Schweitzer 2007), Germany (Bauer et al. 2007), and Italy (Devicienti, Maida, and Sestito 2007). In what follows, we present a brief description of the main elements of this model. 7

The likelihood of each individual wage change observation belongs to one of three possible regimes: a regime subject to DNWR, a regime subject to wage indexation or DRWR, and a regime in which wages are fully flexible. ${ }^{8}$ In the model, we allow for the possibility (although this is not imposed) that observed wage levels are distorted by measurement error. Define $\Delta y_{i t}^{*}$ as the notional wage change distribution at time $t$, corresponding to wage changes between $t$ and $t-1$. The notional is

\footnotetext{
${ }^{7}$ See the online Appendix for a full derivation of the model.

${ }^{8}$ We use the terms DRWR and wage indexation interchangeably. There are important differences across countries, but indexation clauses tend to be asymmetric. If inflation happens to be above expectations, revision clauses are often in place, but the reverse is not true. See Babecky et al. (2012) for a discussion.
} 
the distribution that would prevail if all wages were fully flexible and there were no measurement errors. Then, the notional wage change for a random draw $i$ from the population can be modeled as a function of observable characteristics, as follows:

$$
\Delta y_{i t}^{*}=\mathbf{x}_{i t-1} \boldsymbol{\beta}_{t}+\varepsilon_{i t} .
$$

The vector $\mathbf{x}_{i t-1}$ represents a set of individual and job characteristics in the base year, and the error term $\varepsilon_{i t}$ is assumed to be normally distributed $\left(\varepsilon_{i t} \sim N\left(0, \sigma_{e t}^{2}\right)\right)$. The problem is that we do not observe this notional wage change. Rather than observing $\Delta y_{i t}^{*}$, we observe a wage change distribution that is potentially distorted by both measurement errors and downward wage rigidities. We refer to this distribution as the observed distribution $\left(\Delta y_{i t}^{o}\right)$, and we detail below how it relates to $\Delta y_{i t}^{*}$.

As we stated, the first reason why observed and notional wage changes can differ is the presence of measurement error. The population measurement error is defined as the difference between the observed value, $\Delta y_{i t}^{o}$, and the actual value, $\Delta y_{i t}$. Hence, $\Delta m_{i t}=\Delta y_{i t}^{o}-\Delta y_{i t}$, where $m_{i t}$ is modeled as a shock to wage levels that is independently and normally distributed across individuals and time periods $\left(m_{i t} \sim N\left(0, \sigma_{m t}^{2}\right)\right)$. However, not all wage level observations are subject to measurement error. We assume that with probability $q_{t}$, wage levels at time $t$ are correctly measured, and with probability $1-q_{t}$, they are measured with error.

The second reason why observed and notional wage changes can differ is the presence of rigidities in wage setting. Wage changes for the proportion of individuals subject to DNWR, denoted by $p_{t}^{N}$, will be governed by

$$
\Delta y_{i t}^{o}=\left\{\begin{array}{ll}
\mathbf{x}_{i t-1} \boldsymbol{\beta}_{t}+\varepsilon_{i t}+\Delta m_{i t} & \text { if } \Delta y_{i t}^{*} \geq 0 \\
\Delta m_{i t} & \text { if } \Delta y_{i t}^{*}<0
\end{array}\right\}
$$

Thus, for those individuals subject to DNWR, the observed wage change will coincide with the notional wage change plus some measurement error only when the programmed wage increase is above zero. If the notional wage change were negative, the worker would receive a wage freeze, and the observed wage change would differ from zero only if wages were measured with error.

Similarly, the observed wage changes of the individuals prone to DRWR, denoted by $p_{t}^{R}$, will be given by

$$
\Delta y_{i t}^{o}=\left\{\begin{array}{ll}
\mathbf{x}_{i t-1} \boldsymbol{\beta}_{t}+\varepsilon_{i t}+\Delta m_{i t} & \text { if } \Delta y_{i t}^{*} \geq r_{i t} \\
\Delta m_{i t}+r_{i t} & \text { if } \Delta y_{i t}^{*}<r_{i t}
\end{array}\right\} .
$$

A straightforward interpretation (but not the only one) of $r_{i t}$ is that it represents individual-specific inflation expectations. Note that, in contrast with DNWR, the focal point for wage indexation is individual specific $\left(r_{i t}\right)$. In the empirical implementation of the model, we will assume that $r_{i t}$ is independently and identically distributed normal, and will allow its mean and variance to vary over time $\left(r_{i t} \sim N\left(\mu_{r t}, \sigma_{r t}^{2}\right)\right)$. 
As for the fraction of flexible individuals, denoted by $1-p_{t}^{N}-p_{t}^{R}$, their actual wage changes, $\Delta y_{i t}$, are equal to the notional wage changes, $\Delta y_{i t}^{*}$. Differences between observed and notional wage changes are allowed if measurement error is present: $\Delta y_{i t}^{o}=\Delta y_{i t}^{*}+\Delta m_{i t}$.

The probability of belonging to each of the three regimes-DNWR $\left(p_{t}^{N}\right)$, DRWR $\left(p_{t}^{R}\right)$ and flexible wages $\left(1-p_{t}^{N}-p_{t}^{R}\right)$-is the same across individuals but varies year by year. Since the three probabilities sum up to one, we will often refer to them in the paper as the share of individuals in each regime. Note that these probabilities denote the fraction of the labor force that is potentially constrained by wage rigidity. For instance, the higher $p_{t}^{N}$, the higher the probability that if the individual were scheduled for a wage cut, her wage would be frozen. This is different from the probability of each regime being actually binding, which naturally depends on the notional wage growth of each individual, and consequently on individual characteristics and the macroeconomic environment.

There is not a simple one-to-one correspondence between the shares of the rigidity regimes and the probability of being actually constrained by rigidities. For example, in a hypothetical country that consistently across years displayed the following features: (i) wage change histograms with no wage cuts, (ii) a spike at zero, and (iii) no other observable distortions in wage changes, our estimator would indicate $p_{t}^{N}$ to be in the vicinity of one. However, the actual incidence of DNWR could vary greatly year by year. In years of rapid GDP growth, we would probably observe a smaller spike at zero, and hence lower incidence of DNWR. However, in a recession, the spike at zero would likely be larger, and so would the fraction of workers for whom DNWR is actually binding. Similarly, individual characteristics matter. For example, if productivity growth is higher for managers than for welders, the probability of DNWR being binding (i.e., the probability that the notional wage change falls below 0 ) should be lower for the former group. Hence, the actual incidence of DNWR would be lower for managers than for welders.

Denoting $\Phi$ the cumulative density function of a standard normally distributed variable, the incidence of DNWR $\left(i_{i t}^{N}\right)$ and DRWR $\left(i_{i t}^{R}\right)$ in year $t$ can be obtained as

$$
\begin{aligned}
& i_{i t}^{R}=p_{t}^{R} \Phi\left\{\left(\mu_{r}-\mathbf{x}_{i t-1} \boldsymbol{\beta}_{t}\right) /\left(\sigma_{e t}^{2}+\sigma_{r t}^{2}\right)^{\frac{1}{2}}\right\} \\
& i_{i t}^{N}=p_{t}^{N} \Phi\left\{\mathbf{x}_{i t-1} \boldsymbol{\beta}_{t} / \sigma_{e t}\right\} .
\end{aligned}
$$

Under these assumptions, the contribution of each observation to the likelihood is calculated and all parameters are estimated by maximum likelihood. Intuitively, the estimator uses the local asymmetries in the wage change distributions that we have discussed in the descriptive section to identify DNWR and DRWR. However, instead of identifying them unconditionally by, for example, visually inspecting the previous histograms, the estimator exploits the asymmetries in wage changes conditional on individual and job characteristics. As for the identification of potential measurement error, the estimator has two main features that help assess its relevance. First, since measurement error is expected to follow a continuous distribution, its presence is less likely when the size of the spike at zero or the rate of inflation are large. Second, since measurement error is expected to displace these spikes in the 
distribution, when measurement error is important, we should observe an excess of probability mass around zero and $r_{i}$ and relatively smooth asymmetries in other parts of the wage change distribution. ${ }^{9}$

Note that, in contrast with previous studies, the rate of inflation observed during the period of study in both Uruguay and Brazil is fairly volatile. We exploit this variability to study the impact of disinflation by estimating our model year by year. This allows for a flexible specification, wherein both the parameters of the notional and the different rigidity regimes may vary across years.

Two extensions of the baseline model are examined in the robustness section (Section IV). When indexation is the dominant friction, real wage rigidity may operate upward as well as downward. Hence, we allow for symmetric real wage rigidity. Second, we extend the model to allow for within-group inequality in the notional wage change distribution by letting the variance to be a function of observable worker and firm characteristics. This introduces additional flexibility in the estimation, by not imposing unimodality or symmetry in the notional.

\section{Main Results}

\section{A. Empirical Implementation}

In this section, we discuss some relevant details regarding the empirical implementation of the model and provide a first assessment of its performance. We estimate an individual wage change model and the corresponding rigidity parameters year by year. It is important to note that, after applying the sample restrictions discussed in Section I, we do not eliminate outliers from the sample. We let our model of measurement error deal with the problem of reporting errors.

The set of covariates used to estimate the notional wage change distribution varies in the two countries, reflecting differences in data availability. ${ }^{10}$ The Brazilian data are more comprehensive and allow us to control for gender, age, tenure and their quadratic terms, educational attainment, occupation and sector of operation, establishment size, type of labor contract, and location of the firm (in Belo Horizonte or outside the state capital). In the case of Uruguay, we control for gender, age, tenure and their quadratic terms, sector of operation, white- or blue- collar status, establishment size, and the location of the firm (in Montevideo versus the rest of the country).

Table 1 reports maximum likelihood estimates of the notional wage change equation parameters and their associated z-statistics for Uruguay and Brazil in 1998-1999. ${ }^{11}$ The estimated coefficients are highly significant in almost all cases.

\footnotetext{
${ }^{9}$ It is important to note that not all forms of measurement error will necessarily result in an underestimation of DNWR. Most notably, in the presence of rounding errors, wage freezes would actually be overrepresented and not the opposite (see Smith 2000). We believe our data are unlikely to suffer from rounding errors because wage information is directly extracted from firms' individual pay records. In the case of Uruguay, the BPS data determine individual access to pension, health, and other benefits. Hence, it is in the worker's interest that the firm accurately report all information. Moreover, the data are thoroughly checked by government officials. In the case of Brazil, wages are also directly extracted from company records, and wage information is requested to the level of centavos (cents). On average, 75 percent of our wage observations include the cents paid.

${ }^{10}$ However, using a restricted set of covariates in Brazil that matches those available in Uruguay provided very similar results to those discussed in the text.

${ }^{11}$ Results for the other years are qualitatively similar to those of 1998-1999 unless otherwise stated in the text.
} 
Table 1-Maximum Likelihood Estimates—Notional Wage Growth 1998-1999

\begin{tabular}{|c|c|c|c|c|}
\hline & \multicolumn{2}{|c|}{ Uruguay } & \multicolumn{2}{|c|}{ Brazil } \\
\hline & Coefficient & $\mathrm{z}$ & Coefficient & $\mathrm{z}$ \\
\hline Age & $-0.004 * * *$ & -6.96 & $-0.001 * * *$ & -7.94 \\
\hline $\mathrm{Age}^{2} / 1,000$ & $0.032 * * *$ & 4.61 & $0.002 * * *$ & 4.33 \\
\hline Male & $0.006^{* * *}$ & 3.10 & $-0.001 * * *$ & -3.83 \\
\hline Tenure in months & $-0.001 * * *$ & -13.22 & $0.000 * * *$ & 4.94 \\
\hline$(\text { Tenure in months) })^{2} / 1,000$ & $0.001 * * *$ & 7.74 & $-0.000 * * *$ & -2.75 \\
\hline \multicolumn{5}{|l|}{ Establishment size } \\
\hline 0-5 employees & $-0.116^{* * *}$ & -23.55 & $-0.011 * * *$ & -26.08 \\
\hline 5-15 employees & $-0.091 * * *$ & -20.31 & $-0.007 * * *$ & -18.57 \\
\hline 15-30 employees & $-0.082 * * *$ & -16.95 & $-0.005^{* * *}$ & -11.56 \\
\hline 30-50 employees & $-0.047 * * *$ & -9.63 & $-0.001 * * *$ & -1.28 \\
\hline 50-100 employees & $-0.018 * * *$ & -4.17 & $0.004 * * *$ & 9.28 \\
\hline 100-200 employees & $-0.022 * * *$ & -4.68 & $0.004 * * *$ & 9.69 \\
\hline 200-500 employees & $-0.033 * * *$ & -7.30 & $0.005^{* * *}$ & 13.28 \\
\hline 500-1,000 employees & $-0.009 * *$ & -2.14 & $0.009 * * *$ & 18.90 \\
\hline Montevideo & $0.009 * * *$ & 4.00 & - & - \\
\hline Belo Horizonte & - & - & $0.004 * * *$ & 18.23 \\
\hline White collar worker & $0.008 * *$ & 2.41 & - & - \\
\hline Occupation dummies & - & - & Yes & \\
\hline Temporary contract & - & - & -0.002 & -1.46 \\
\hline \multicolumn{5}{|l|}{ Education } \\
\hline Primary & - & - & $-0.001 * * *$ & -3.81 \\
\hline Secondary & - & - & 0.000 & 0.06 \\
\hline Observations & \multicolumn{2}{|c|}{71,539} & \multicolumn{2}{|c|}{$1,005,791$} \\
\hline
\end{tabular}

Notes: The reference groups for establishment size and education are more than 1,000 employees and tertiary education, respectively. Additional control variables are 9 sector dummies for Uruguay and 14 sector dummies and 9 occupation dummies for Brazil.

*** Significant at the 1 percent level.

** Significant at the 5 percent level.

* Significant at the 10 percent level.

Some commonalities within the two countries emerge. As expected, individual wage growth declines nonmonotonically with age, is higher in the capital, and tends to increase with establishment size, although wages in medium to large Brazilian establishments (those with 50 to 1,000 employees) display higher wage growth than the largest firms in the sample (those with 1,000 employees or more). Perhaps surprisingly, the effects of education and type of contract on individual wage growth in Brazil are not clear, as suggested by inconsistent signs across years and coefficients that are often statistically insignificant.

Figure 5 presents the wage changes predicted by the model, as well as the observed wage changes in 1997-1998. Panel A displays the corresponding distributions for Uruguay and panel B displays the corresponding distributions for Brazil. The predicted histogram is obviously smoother, but the overall fit of the model to the shape of the observed wage growth histogram is quite good. If anything, the model tends to underestimate the concentration of observations around the focal points of rigidity. In the case of Uruguay, we slightly underestimate the spike at zero and overestimate the share of wage growth observations immediately below the focal point of real rigidity. In the case of Brazil, we slightly underestimate the concentration of observations around the realized rate of inflation. Table 2 compares the median and standard deviations in the observed and estimated distributions in every year. With very few 

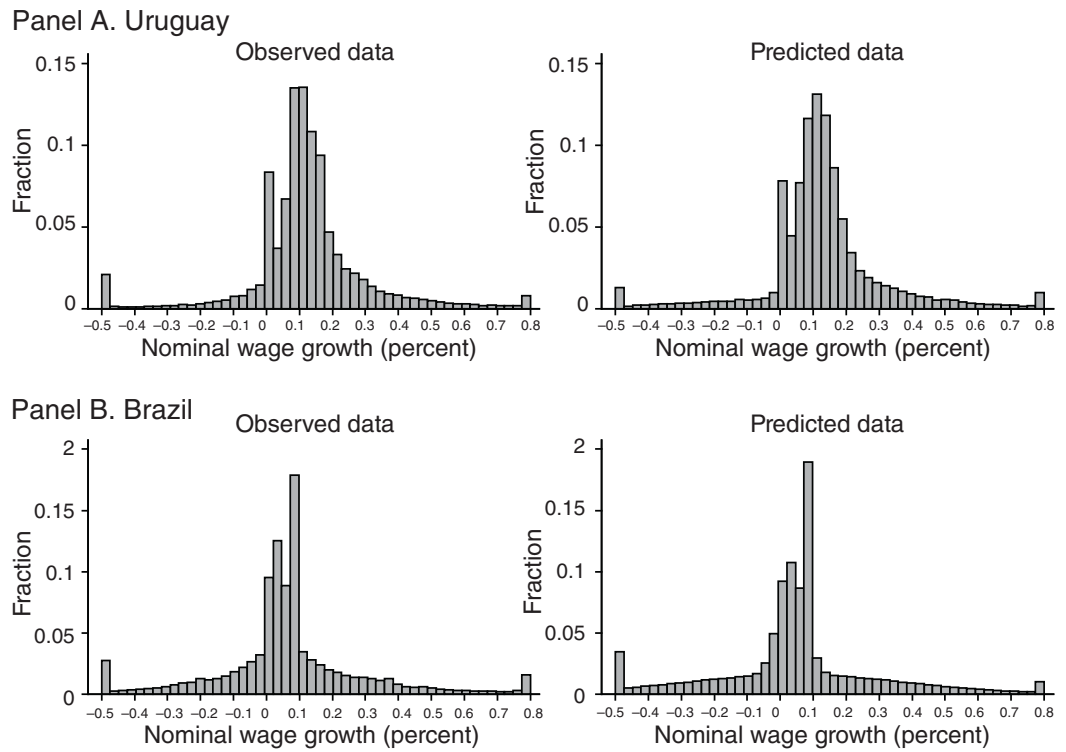

Figure 5. Observed versus Predicted Log Hourly Wage Changes, 1997-1998

Note: The first (last) bin in each histogram corresponds to the frequency of all the observations with an annual growth below (above) $-0.5(0.8)$.

exceptions, the model fit is very close to the actual summary statistics. We pin down the median and standard deviations with a precision up to the second decimal.

Tables 3 and 4 summarize some other important parameter estimates from our model, including the mean wage changes in the observed $\left(\Delta y_{i t}^{o}\right)$ and notional $\left(\Delta y_{i t}^{*}\right)$ distributions, the estimated focal point of DRWR, the percentages of workers subject to DNWR $\left(p_{t}^{N}\right)$ and DRWR $\left(p_{t}^{R}\right)$, and the extent of measurement error in the data $\left(q_{t}\right)$. Regarding the latter, our results indicate that measurement error in the data is quite stable over time in both countries. On average, the share of hourly wage changes that are reported with error according to the model is 21 percent in Brazil, against 9 percent in Uruguay. Goette, Bauer, and Sunde (2007) note that their estimator may encounter identification problems when inflation is very low because, in that case, DNWR and DRWR are very close in the wage change distribution and are therefore hard to distinguish. This turns out not to be a problem in our case. The estimated focal point of real wage rigidity $\left(r_{i}\right)$ is always well above zero.

\section{B. Downward Real and Nominal Rigidity}

We begin the discussion of our main results by assessing the impact of measurement error on the shares of nominal wage freezes and cuts. In line with our expectations, the share of wage cuts declines and the share of wage freezes increases after measurement errors have been dealt with, as the comparisons plotted in Figures 6 and 7 show for Uruguay and Brazil, respectively. The average share of wage cuts in the data is quite large: 16 percent in Uruguay and 18 percent in Brazil. However, these shares are almost halved, to 9 percent in Uruguay and to 10 percent in Brazil, 
Table 2-Observed versus Simulated Wage Change Distributions

\begin{tabular}{|c|c|c|c|c|}
\hline & \multicolumn{2}{|c|}{ Actual wage growth } & \multicolumn{2}{|c|}{ Ratio actual/simulated } \\
\hline & Median & SD & Median & SD \\
\hline Year & \multicolumn{4}{|c|}{ Uruguay } \\
\hline 1996-1997 & 0.175 & 0.334 & 0.99 & 1.08 \\
\hline 1997-1998 & 0.113 & 0.197 & 0.97 & 0.99 \\
\hline 1998-1999 & 0.068 & 0.294 & 1.00 & 1.06 \\
\hline 1999-2000 & 0.033 & 0.300 & 1.00 & 1.11 \\
\hline 2000-2001 & 0.025 & 0.319 & 1.31 & 1.11 \\
\hline 2001-2002 & 0.004 & 0.340 & 0.80 & 1.07 \\
\hline $2002-2003$ & 0.010 & 0.260 & 0.55 & 1.06 \\
\hline \multirow[t]{2}{*}{$2003-2004$} & 0.057 & 0.264 & 1.06 & 1.06 \\
\hline & \multicolumn{4}{|c|}{ Brazil } \\
\hline 1995-1996 & 0.134 & 0.292 & 0.95 & 1.02 \\
\hline 1996-1997 & 0.077 & 0.282 & 1.02 & 1.03 \\
\hline 1997-1998 & 0.055 & 0.265 & 1.06 & 1.04 \\
\hline 1998-1999 & 0.045 & 0.281 & 1.00 & 1.07 \\
\hline 1999-2000 & 0.094 & 0.267 & 1.04 & 1.01 \\
\hline 2000-2001 & 0.100 & 0.248 & 0.99 & 1.03 \\
\hline 2001-2002 & 0.104 & 0.248 & 1.00 & 1.02 \\
\hline
\end{tabular}

Table 3-Downward Nominal and Real Wage Rigidity in Uruguay-Parameter Estimates

\begin{tabular}{lrrrccccc}
\hline \hline Year & $\Delta y_{i}^{o}$ & $\Delta y_{i}^{*}$ & $\mu_{r}$ & $\sigma_{r}$ & $p^{R}$ & $p^{N}$ & $1-q$ & $N$ \\
\hline $1996-1997$ & 0.182 & 0.072 & 0.160 & 0.049 & 0.722 & 0.117 & 0.048 & 52,222 \\
$1997-1998$ & 0.120 & -0.064 & 0.105 & 0.047 & 0.882 & 0.118 & 0.124 & 70,254 \\
$1998-1999$ & 0.069 & -0.018 & 0.063 & 0.001 & 0.651 & 0.183 & 0.067 & 71,556 \\
$1999-2000$ & 0.036 & 0.024 & 0.178 & 0.003 & 0.122 & 0.613 & 0.102 & 69,352 \\
2000-2001 & 0.015 & 0.014 & 0.207 & 0.000 & 0.067 & 0.620 & 0.101 & 68,149 \\
2001-2002 & -0.016 & -0.001 & 0.164 & 0.000 & 0.080 & 0.624 & 0.135 & 66,525 \\
2002-2003 & 0.041 & 0.009 & 0.248 & 0.000 & 0.072 & 0.678 & 0.093 & 63,996 \\
2003-2004 & 0.088 & 0.049 & 0.084 & 0.002 & 0.044 & 0.750 & 0.077 & 63,497 \\
\hline
\end{tabular}

Note: This table displays the mean wage changes in the observed $\left(\Delta y_{i}^{o}\right)$ and notational $\left(\Delta y_{i}^{*}\right)$ distributions, the mean of the estimated focal point of DRWR $\left(\mu_{r}\right)$ and its variance $\left(\sigma_{r}\right)$, the percentages of workers in the DRWR $\left(p^{R}\right)$ and DWNR $\left(p^{N}\right)$ regimes, the share of wage change observations observed with error $(1-q)$, and the number of observations $(N)$ for each period.

Table 4-Downward Nominal and Real Wage Rigidity in BraZIL-Parameter Estimates

\begin{tabular}{lcccccccr}
\hline \hline Year & $\Delta y_{i}^{o}$ & $\Delta y_{i}^{*}$ & $\mu_{r}$ & $\sigma_{r}$ & $p^{R}$ & $p^{N}$ & $1-q$ & $N$ \\
\hline 1995-1996 & 0.174 & 0.136 & 0.113 & 0.000 & 0.457 & 0.009 & 0.219 & 849,004 \\
$1996-1997$ & 0.122 & 0.074 & 0.069 & 0.000 & 0.493 & 0.026 & 0.298 & 896,797 \\
$1997-1998$ & 0.065 & 0.032 & 0.080 & 0.000 & 0.306 & 0.041 & 0.312 & 985,980 \\
$1998-1999$ & 0.078 & 0.040 & 0.045 & 0.000 & 0.312 & 0.091 & 0.258 & $1,005,791$ \\
$1999-2000$ & 0.113 & 0.007 & 0.078 & 0.030 & 0.659 & 0.082 & 0.063 & $1,042,319$ \\
2000-2001 & 0.126 & 0.101 & 0.056 & 0.004 & 0.271 & 0.351 & 0.207 & $1,085,804$ \\
2001-2002 & 0.126 & 0.064 & 0.099 & 0.009 & 0.530 & 0.093 & 0.110 & $1,199,888$
\end{tabular}

Note: This table displays the mean wage changes in the observed $\left(\Delta y_{i}^{o}\right)$ and notational $\left(\Delta y_{i}^{*}\right)$ distributions, the mean of the estimated focal point of DRWR $\left(\mu_{r}\right)$ and its variance $\left(\sigma_{r}\right)$, the percentages of workers in the DRWR $\left(p^{R}\right)$ and DWNR $\left(p^{N}\right)$ regimes, the share of wage change observations observed with error $(1-q)$, and the number of observations $(N)$ for each period. 


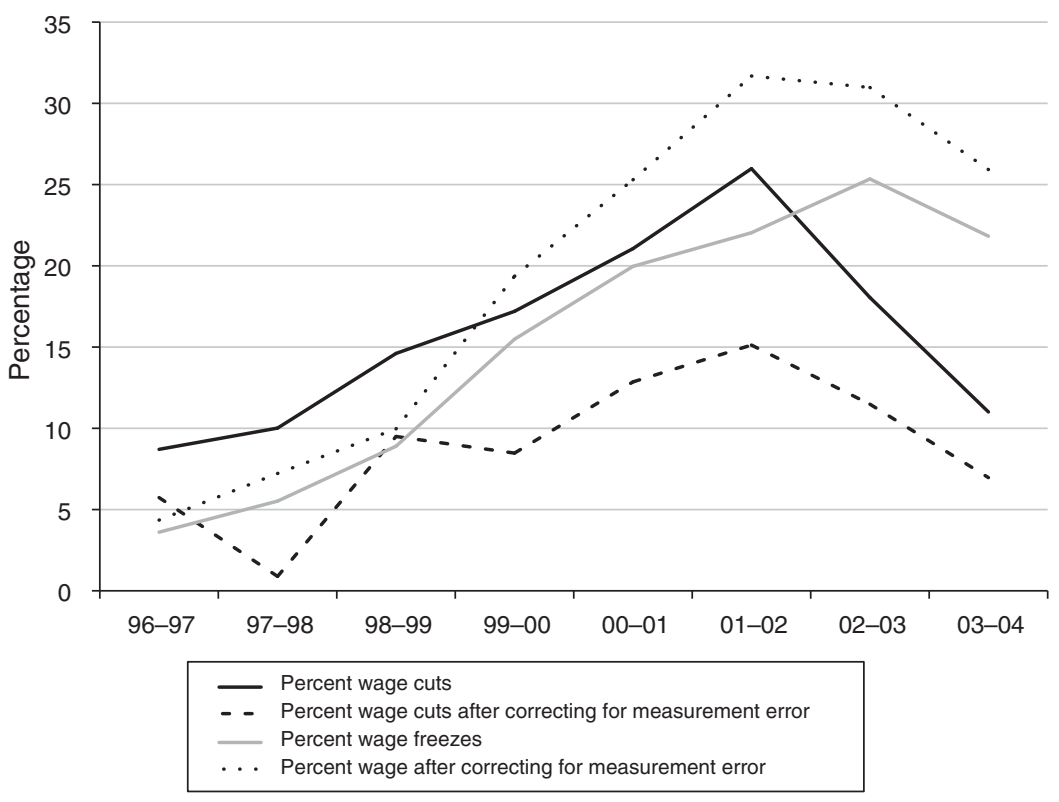

Figure 6. Wage Cuts and Freezes in Uruguay, the Impact of Measurement Error

when measurement error has been taken into account. Over time, the share of wage cuts gradually increases in Uruguay (Figure 6), in accordance with the disinflation process. However, the increase in wage cuts in Uruguay should not necessarily be interpreted as a sign of increased wage flexibility, inasmuch as wage freezes also rise over the same period - a feature consistent with growing importance of DNWR. In the data, wage freezes move from 3.6 percent in 1996-1997 to 25 percent in 2002-2003. The rise is even more dramatic after measurement error has been accounted for, moving from 4.4 percent to 31 percent within the same period. We do not observe a clear pattern in the time evolution of wage cuts and freezes in Brazil as we did in Uruguay (Figure 7).

In contrast with previous evidence for OECD countries, we observe a sharp regime change regarding the type of rigidity prevailing in Uruguay that coincides with the progressive disinflation process. This is illustrated in Figure 8. In the first years of our sample period, DRWR is very important, most likely as a result of a recent history of high inflation and widespread indexation in labor contracts. The share of workers in the real rigidity regime $\left(p^{R}\right)$ is 72 percent in 1996-1997 and 88 percent in 1997-1998. As inflation goes down, however, real rigidity rapidly declines. In 1998-1999, the share of workers subject to the real rigidity regime is 65 percent. This plummets to 12 percent the next year and remains relatively stable below 8 percent, for the remainder of the period.

Importantly, the decline of DRWR does not lead the way to a frictionless wagesetting mechanism. Instead, as inflation declines in Uruguay, we observe a sharp rise in the share of workers subject to DNWR. During the first two years of wage changes, DNWR is very low according to our estimates: the fraction of workers subject to DNWR is just 12 percent. After a mild increase in 1998-1999, DNWR jumps 


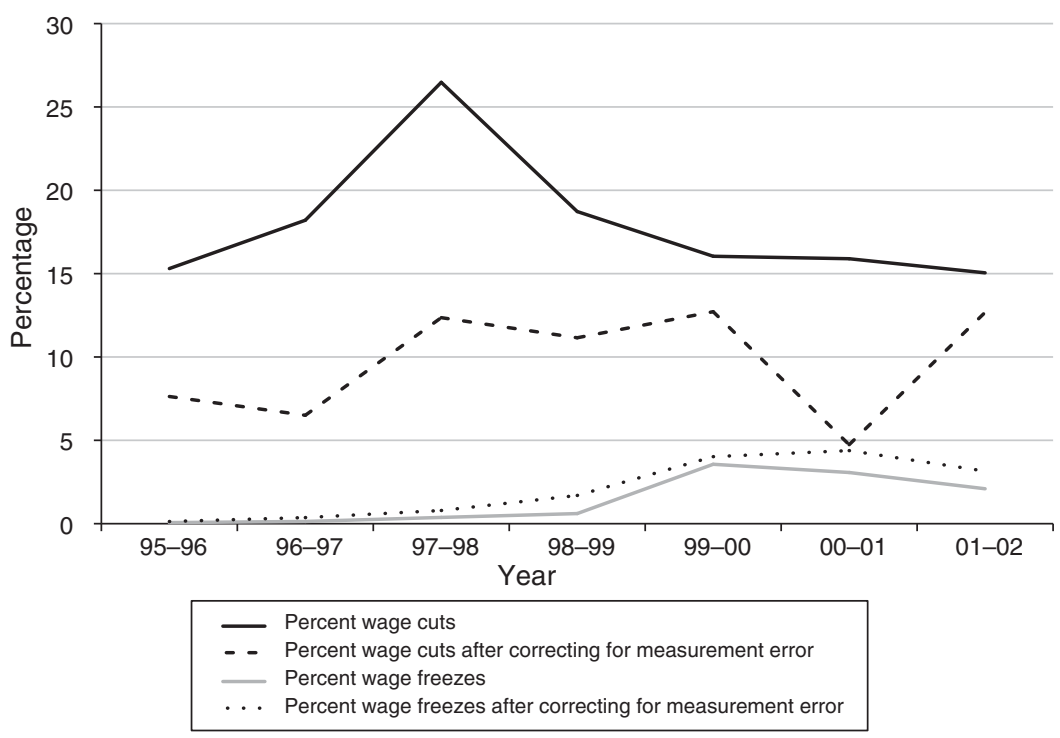

Figure 7. Wage Cuts and Freezes in Brazil, the Impact of Measurement Error

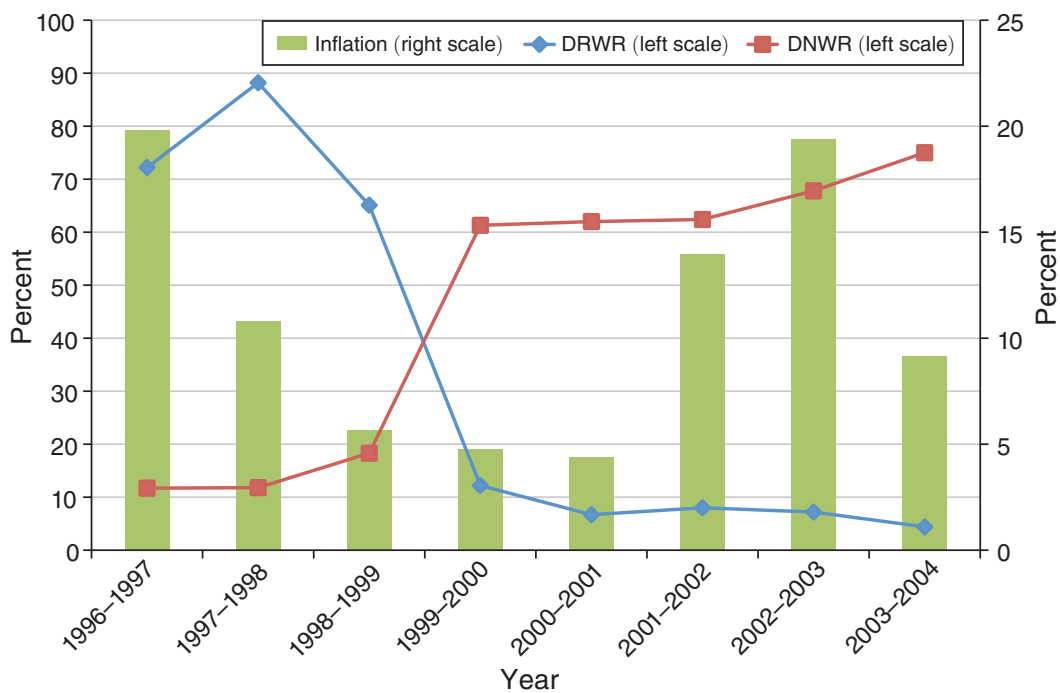

Figure 8. Rigidity Regimes and the Rate of Inflation In URUgUaY

to a new equilibrium in 1999-2000, when the share of workers subject to DNWR stabilizes at around 65 percent for the remainder of the period. However, the relationship between the two types of rigidities and inflation is more complex than one might initially suspect. When inflation peaks again in 2001-2002 and 2002-2003, the share of workers subject to DRWR remains low, while DNWR is still binding for most of the labor force $\left(p_{2001-2002}^{N}=62\right.$ percent and $p_{2002-2003}^{N}=78$ percent $)$.

Note that this is the same period in which the share of both wage cuts and freezes grows sharply in Uruguay. The rationale for this behavior must be found in the severe recession in Uruguay during these years. Uruguay entered into a long recession 
in 1998:IV that reached its trough in 2002:III, after a temporary upswing between 2000:II and 2001:III. ${ }^{12}$ In 2002, the severe crisis that affected the economy forced the central bank to let the exchange rate float freely, putting an end to the use of the exchange rate as a nominal anchor. Hence, even in the presence of high inflation during these years, firms needed downward wage adjustments. Perhaps more importantly, 2003-2004 displayed a very strong recovery in economic activity (real GDP growth was 12 percent) and relatively high inflation (9 percent). Even in this context, wage indexation does not reappear, and DNWR remains as the only noticeable friction in wage setting $\left(p_{2003-2004}^{N}=78\right.$ percent and $p_{2003-2004}^{R}=4$ percent $)$. That DRWR does not return as a wage-setting friction even in a relatively high inflation environment reinforces the interpretation of the move toward DNWR as a regime shift.

Results in Brazil also suggest substantial frictions in wage setting, but in contrast with Uruguay, these appear to be highly persistent over time and heavily tilted toward real rigidity. The share of workers subject to DRWR throughout the sample period is high, while DNWR is of second-order importance. On average, 43 percent of the formal workforce in Brazil is subject to the downward real rigidity regime (see Table 4). In contrast, the probability of being subject to DNWR is below 10 percent. Although the share of workers subject to the two regimes fluctuates somewhat from year to year, they never reverse, and DRWR is always the dominant wage-setting regime.

The recent experience in Brazil and Uruguay shows that disinflation does not necessarily translate into more flexible wage-setting mechanisms. In the two countries, the share of workers subject to some sort of friction (nominal or real) remains high in spite of a prolonged period of moderate inflation. Moreover, changes in the frictions associated with wage setting are very different in the two countries. Why did disinflation lead to a rapid decline in real rigidity in Uruguay but not in Brazil? The answer is most likely linked to labor market institutions. In particular, strong unions in Brazil and a rapid movement toward wage decentralization in Uruguay during the sample period are the primary suspects.

Strong unions are likely to have the bargaining power to ensure compensation for inflation, and they are empirically associated with higher DRWR across OECD countries (Dickens et al. 2007; Holden and Wulfsberg 2009). In Uruguay, unionization weakened dramatically during the sample period. In 1992, the government dismantled the Consejos de Salarios, a tripartite system that involved government representatives, unions, and employers' associations in highly centralized wage negotiations. This institutional change drastically reduced the bargaining power of unions, resulting in the virtual disappearance of collective bargaining (Zunino 2009). The unionization rate in the private sector moved progressively from 28 percent in the early 1990s to 8 percent by 2000 (Senatore-Camerota 2007).

More importantly, the dismantling of wage councils meant that collective agreements no longer covered the vast majority of workers in the private sector. On the contrary, this process resulted in a more decentralized wage-setting system, in which individual negotiations became the norm (Cassoni, Labadie, and Fachola 2002). In contrast, extension mechanisms (a system where the agreement of the bargaining

\footnotetext{
${ }^{12}$ Peaks and troughs are identified using the Bry-Boschan quarterly (BBQ) algorithm (Harding and Pagan 2002) on quarterly real GDP data for the period 1988:I-2010:III.
} 
parties is extended to all workers in the sector and region independently of their union status) are automatic in Brazil and did not change during the period of analysis. Just as in France or Spain, this practice explains the high bargaining power of unions in wage negotiations in spite of the low unionization rates (Arbache 2002).

Thus, the strong disinflation process in the two countries takes place in highly heterogeneous labor markets. Relatively centralized wage negotiations in Brazil and widespread extension clauses appear to have prevented wage indexation from declining. Decentralized wage setting and weakened unions in Uruguay instead plausibly eliminated workers' ability to protect their wages from inflation.

We move now to describe the actual incidence of wage rigidities in the two countries. In Uruguay, the fraction of the labor force whose wage growth is constrained on account of protection from real wage cuts declines quite dramatically over time, while the fraction of workers whose wages are constrained by DNWR increases gradually (see Figure 9). Indeed, throughout the 2000s, the probability of being constrained by DNWR is always higher than the probability of being subject to real wage rigidities. Instead, the incidence of the two types of wage rigidity in Brazil is stable over time, confirming the evidence discussed previously regarding the fraction of workers in each rigidity regime (see Figure 10). In spite of the important disinflation process, the probability of being constrained by real wage rigidities changes very little over time and, with the exception of year 2000, lies always above the upper limit of the confidence interval associated with the estimated probability of being subject to DNWR.

To summarize, wage-setting frictions in Brazil and Uruguay are important. In Uruguay, only one in every five workers belongs to a flexible wage-setting regime. The remaining 80 percent are either protected from nominal wage cuts or have their wages indexed to expected inflation. To put this number in perspective, this is on the higher end of previous estimates from high-income countries obtained using a similar methodology: 68 percent of prevalence of either type of rigidity in Germany, 71 percent in Italy, and 45 percent in the United Kingdom. ${ }^{13}$ In contrast with previous studies, we do find a major structural break in the rigidity regime over time. The predominance of the downward real rigidity regime during 1996-1999, affecting 3 out of 4 workers in the formal sector, is followed by a new rigidity regime where protection against nominal wage cuts strongly dominates (amounting to 68 percent against only 6 percent of workers subject to DRWR). The incidence of downward wage rigidities in Brazil is lower, involving 53 percent of the workforce, but the type of wage friction (overwhelmingly DRWR) is more in line with the more unionized European countries.

\section{Monetary Policy Regime and the Indexation of Wages}

The stability of wage indexation in Brazil hides an important regime change. Figure 11 shows the evolution of our estimated focal point of DRWR $\left(r_{i t}\right)$ and its variance, together with the CPI inflation rate and the increase in the minimum wage. In the first years of our sample period, $r_{i}$ traces the increase in the minimum wage almost perfectly. The importance of the minimum wage is so powerful as a focal

\footnotetext{
${ }^{13}$ See Bauer et al. (2007); Devicienti, Maida, and Sestito (2007); and Barwell and Schweitzer (2007) for Germany, Italy, and the United Kingdom, respectively.
} 


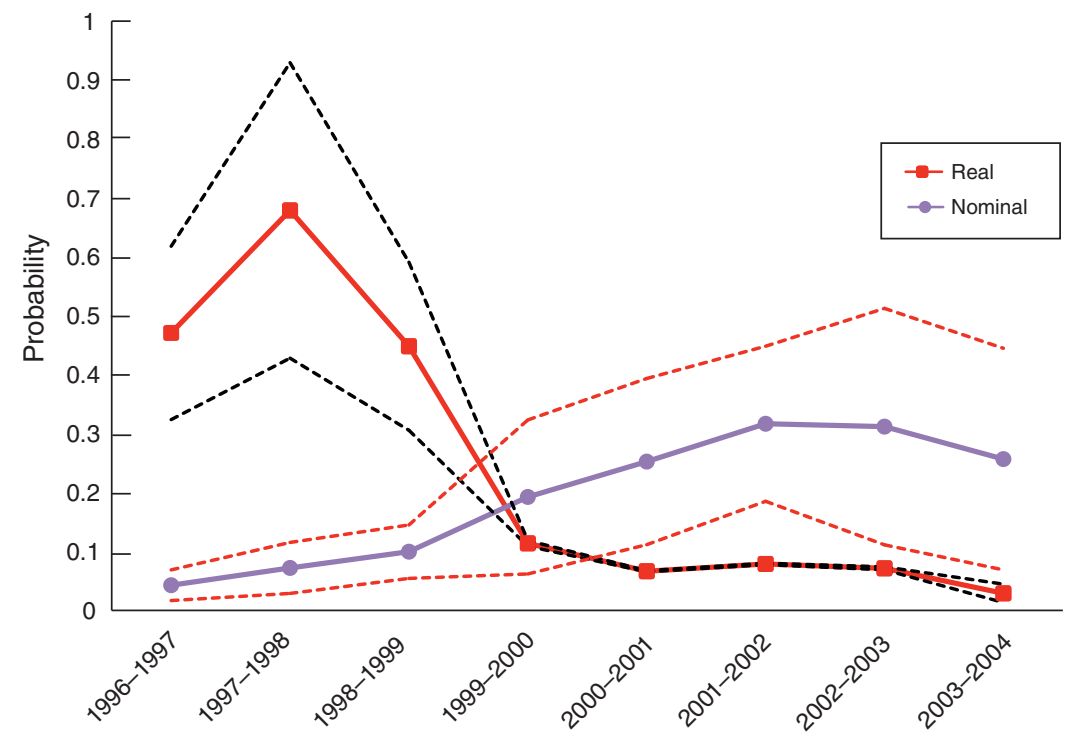

Figure 9. The Incidence of Nominal and Real Wage Rigidities in URUguaY

Notes: The solid lines represent the average probability of being subject to DNWR and DRWR, following equation (4) in the text. Dotted lines are 95 percent confidence intervals.

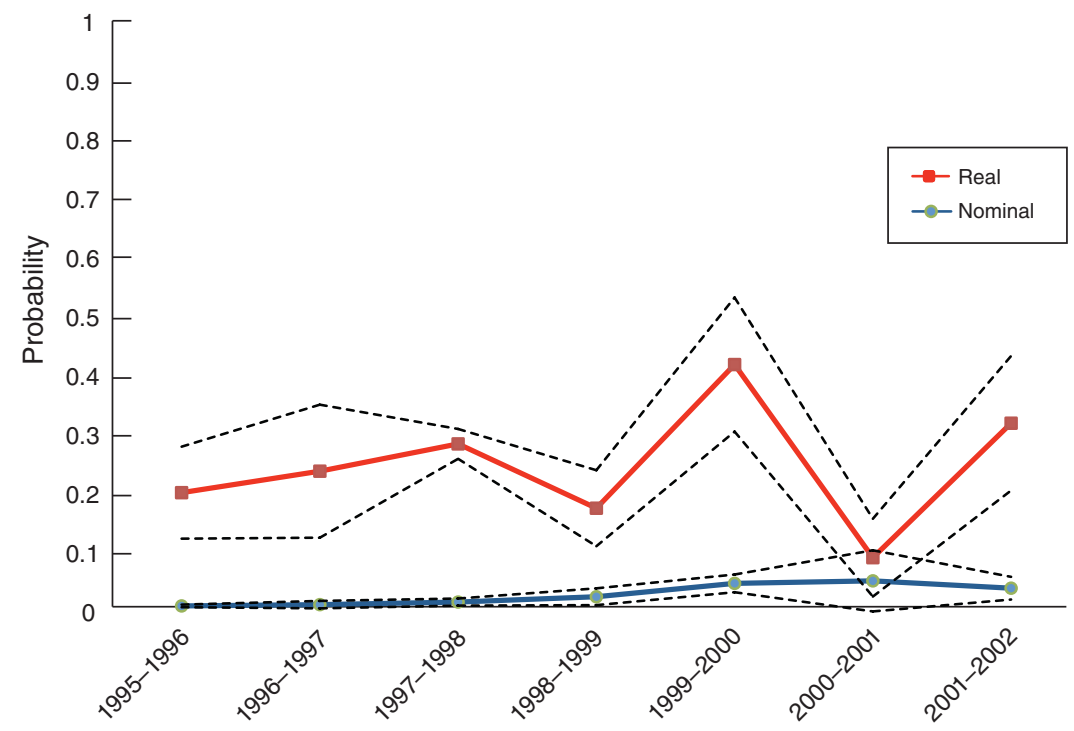

Figure 10. The Incidence of Nominal and Real Wage Rigidities in BraziL

Notes: The solid lines represent the average probability of being subject to DNWR and DRWR, following equation (4) in the text. Dotted lines are 95 percent confidence intervals. 


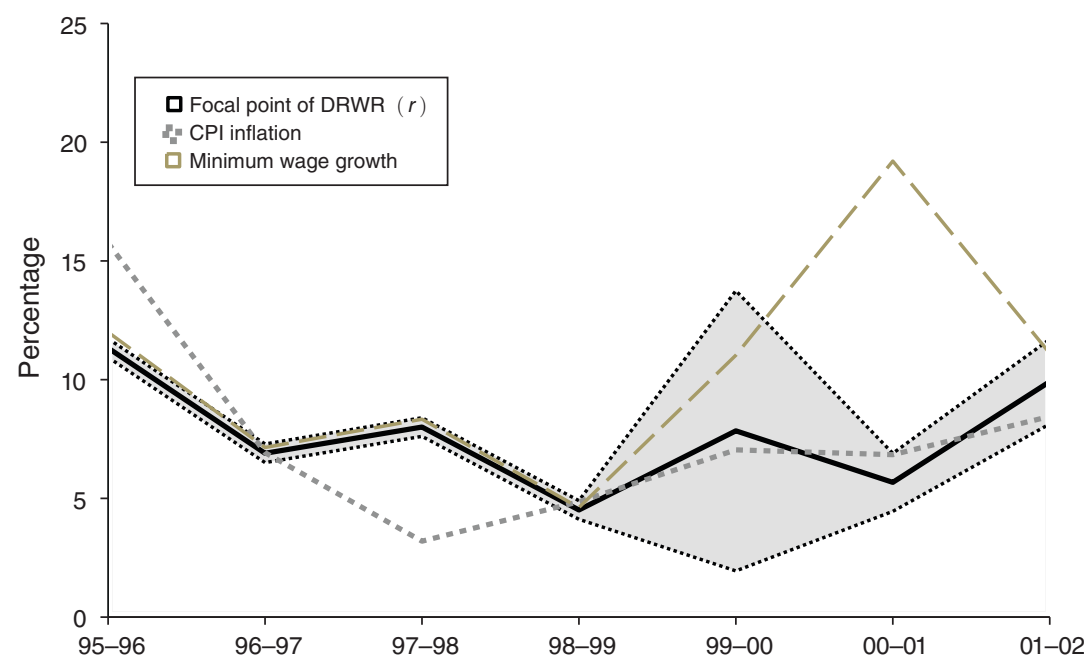

Figure 11. Estimated Focal Point of DRWR and the Rate of Inflation, Brazil

point of wage negotiations that the estimated bounds around $r_{i}$, as measured by its variance, are virtually zero. It is not until 1999-2000 that our estimate of $r_{i}$ starts following the rate of inflation and not the growth of the minimum wage. Incidentally, this is the year in which the Brazilian central bank introduced inflation targeting. The movement away from the minimum wage as the sole price index in wage negotiations, and toward the rate of inflation, speaks in favor of the role of inflation targeting in anchoring inflation expectations.

Interestingly, after the introduction of inflation targeting, the confidence bands around $r_{i}$ widen. A plausible interpretation of the increase in the bands around $r_{i}$ is that they illustrate the dispersion in inflation expectations across agents. Indeed, after 1999-2000, our estimator centers the focal point of wage negotiations at the realized rate of inflation, reinforcing this interpretation. However, the increase in the variance of $r_{i}$ allows indexation to be driven by both distortions around the rate of inflation, and distortions associated with the increase of the minimum wage. The growth of the minimum wage falls outside the estimated range of $r_{i}$ only in 2000-2001, a year in which wage rigidities are narrowly pegged to the inflation rate. It is probably for this reason that we fail to capture the full picture of real rigidity during this year, as illustrated by the rapid drop in the share of workers subject to DRWR.

In contrast with Brazil, the focal point of DRWR in Uruguay when wage indexation is important (i.e., between 1997 and 1999) is much more dispersed across agents (Figure 12). Dispersion in Uruguay is certainly higher than in Brazil during the period in which $r_{i}$ is pegged to the minimum wage, but perhaps more importantly, it is even three orders of magnitude higher than that observed in Brazil after the central bank started targeting inflation. If one interprets $r_{i}$ as an index of inflation expectations in Uruguay, this result would provide further evidence suggesting that the introduction of inflation targeting in Brazil had a powerful impact in anchoring inflation expectations, and, hence, in reducing uncertainty about future inflation. However, as a consequence of the high uncertainty around $r_{i}$ in Uruguay, we cannot 


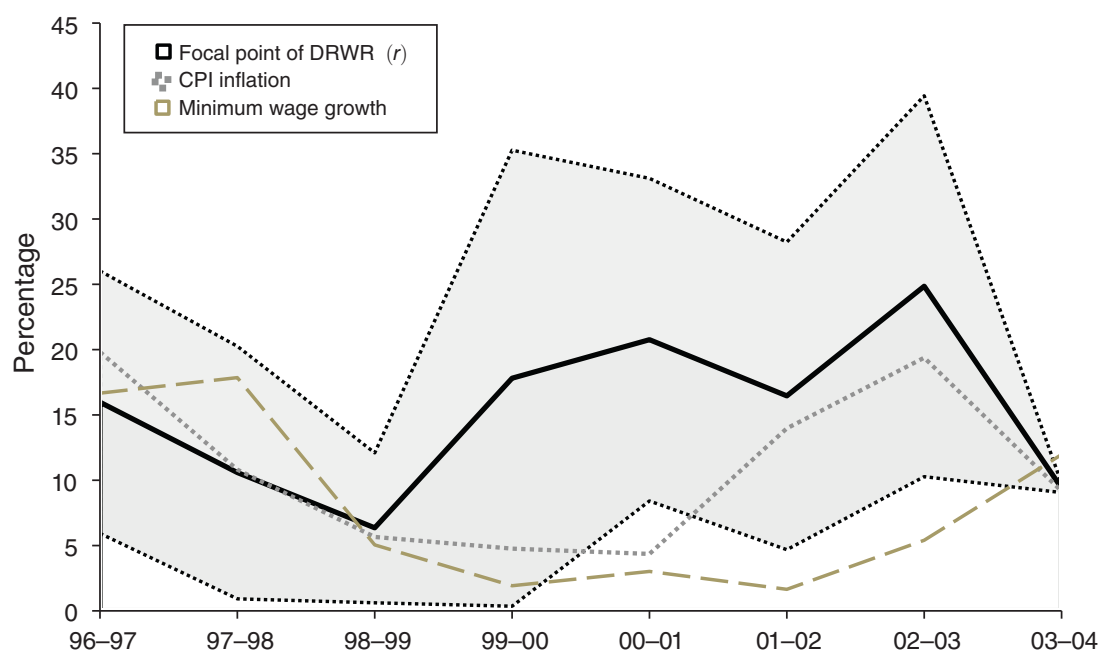

Figure 12. Estimated Focal Point of DRWR and the Rate of Inflation, Uruguay

reject the possibility that the focal point of wage negotiations is related either to the minimum wage or to the rate of inflation throughout most of the sample.

The evolution of the focal point of wage negotiations in Brazil allows us to draw two conclusions. First, even if the extent of DRWR might not vary much over time, the nature of wage rigidities may change. The introduction of a credible inflation target by the central bank anchored inflation expectations and, as a consequence, agents started negotiating wage changes according to their inflation expectations. Second, the monetary policy regime is obviously not the only determinant of wage rigidities; labor market institutions are crucial, too. The minimum wage in many Latin American countries has become a fundamental reference price, which is often used as a norm or numeraire even across those sectors that are theoretically uncovered (Maloney and Mendez 2004). Minimum wages in Brazil were subject to continual adjustments during the high-inflation years in an attempt to preserve their purchasing power. ${ }^{14}$ Our analysis suggests that this triggered an indexation of wages to changes in the minimum wage that persisted even after inflation was under control. Only the introduction of a credible inflation target appears to have managed to partially erode the importance of the minimum wage as an indexation device in the labor market.

\section{Robustness}

In this section, we relax two important assumptions of our baseline model. First, we allow for the variance of the notional wage change distribution to depend on

\footnotetext{
${ }^{14}$ Indeed, the Brazilian 1988 Constitution states that the minimum wage should "maintain its purchasing power" but explicitly forbids the indexation of contracts to changes in the minimum wage. These restrictions do not appear to have been applied in practice, and changes in the minimum wage have been shown to have a large impact on aggregate prices (Lemos 2006).
} 
individual and firm characteristics. Second, we estimate an alternative model in which real wage rigidities are symmetric, that is, either upward or downward.

\section{A. Heteroskedasticity}

Our baseline model assumes that the notional wage change distribution follows the process

$$
\Delta y_{i t}^{*}=\mathbf{x}_{i t-1} \boldsymbol{\beta}_{1 t}+\varepsilon_{i t},
$$

where $\varepsilon_{i t} \sim N\left(0, \sigma_{\varepsilon}\right)$. Hence, residual notional wage change inequality is independently and identically distributed across individuals. However, this may not be the case. Some labor market groups may be more insecure than others, or they may display larger variation in terms of their unobserved characteristics. The baseline model can be easily extended to allow the within-group variance to depend on observable characteristics as follows:

$$
\sigma_{i t}^{2}=\mathbf{z}_{i t-1} \boldsymbol{\beta}_{2 t},
$$

where $\mathbf{z}_{i t-1}$ is a subset of the covariates that govern between-group differences $\left(\mathbf{x}_{i t-1}\right)$, although vectors $\mathbf{x}$ and $\mathbf{z}$ may coincide. Maximum likelihood estimates are obtained by iteration, following the two-step method proposed by Aitkin (1987).

Estimates of the residual $(\log )$ variance of wage changes suggest that within-group differences are indeed important. Consistently across years, we find that the variance of wage changes is a concave function of age, increases with the level of schooling, and is higher for males. However, allowing for heteroskedasticity in the notional wage change distribution has a negligible impact on the key parameters of the model..$^{15}$

\section{B. Real Wage Rigidity: Downward or Symmetric?}

Our baseline model assumes away the possibility of upward wage rigidities. This is a natural assumption in the context of DNWR, and worker resistance to nominal wage cuts is well grounded in theory. ${ }^{16}$ The empirical literature studying real rigidity has also concentrated on asymmetric (downward) frictions (Dickens et al. 2007). However, real wage rigidity, and in particular wage indexation of the type observed in Brazil in the first years of disinflation, may well be symmetric. Workers and firms may agree on implicit or explicit contracts indexed to a price index (e.g., the minimum wage) that are to be applied regardless of worker performance.

The benchmark model can be modified to accommodate symmetric real rigidity. The sole difference is that now all agents who belong to the real rigidity regime $\left(p_{t}^{R}\right)$ will obtain a wage change equal to $r_{i}$ regardless of their notional wage change.

\footnotetext{
${ }^{15}$ See the online Appendix for details.

${ }^{16}$ Firms may be aware of workers' nominal loss aversion (Kahneman and Tversky 1979) or workers' effort and morale may be governed by nominal fairness standards (Kahneman, Knetsch, and Thaler 1986; Bewley 1999). See Campbell and Kamlani (1997) for a discussion.
} 
As before, we allow for the wage bargaining index to differ across agents, possibly reflecting differences in inflation expectations. Hence, equation (3) simplifies to

$$
\Delta y_{i t}^{o}=\Delta m_{i t}+r_{i t}
$$

for agents subject to real wage rigidity (RWR). This implies that this model can be seen as a special case of the benchmark model, in which the upper bound of the wage change for workers in the $p_{t}^{R}$ regime (previously infinity) now coincides with the lower bound at $r_{i t} \sim N\left(\mu_{r}, \sigma_{r}^{2}\right)$.

The results from the restricted model are broadly consistent with the benchmark, although some differences are apparent. The behavior of the focal point of wage negotiations, governed by $\mu_{r}$ and $\sigma_{r}$, is virtually identical in the two models (see Table 5). As before, the focal point of wage negotiations is tightly linked to the minimum wage up to 1999 and starts following (with a higher variance across agents) the rate of inflation after the introduction of inflation targeting in 1999. Also in line with the benchmark, real wage rigidity continues to be the dominant friction in Brazil. However, the share of workers subject to symmetric real rigidity is lower than the share of workers subject to DRWR previously estimated. On average, 25 percent of the workforce belongs to the RWR regime when both downward and upward rigidity are considered, as opposed to 43 percent if real rigidity is only allowed to operate downward. The Akaike information criterion favors the model featuring DRWR in five out of the seven years of wage changes for which the model was estimated. Hence, we conclude that results are fairly robust to the modeling of real rigidity.

\section{From Micro to Macro Rigidities}

Our wage rigidity measures thus far are derived from wage changes of individuals engaged in ongoing employment relationships. But Latin American countries (and Brazil is no exception) are characterized by high worker turnover rates-even larger than in developed economies (Haltiwanger, Scarpetta, and Schweiger 2010). In this context, wage rigidity for job stayers may not translate into similar levels of rigidity at higher levels of aggregation. Firms hit by a negative shock that are hindered by downward wage rigidities are more likely to use other margins of adjustment to modify their unit labor costs. Replacing older workers by younger (and, hence, lower paid) new entrants, changing shift assignments, and slowing down promotions are just some examples (Babecký et al. 2012). Thus, are micro rigidities observable at the macro level in Brazil? To shed some light on this question, we analyze wage changes between two consecutive years in detailed occupations using the PNAD, a household survey representative of the Brazilian economy. ${ }^{17}$

Figure 2, initially introduced in Section I, shows kernel estimates of wage changes in occupations from the PNAD for formal and informal workers. ${ }^{18}$ A striking aspect of the distributions is their smoothness. Compared with the histograms of individual wage changes (Figures 3 and 4), we do not observe distortions in wage changes

\footnotetext{
${ }^{17}$ See Section I for a description of the main characteristics of the PNAD.

${ }^{18}$ See Section I for data details.
} 
Table 5-Robustness Check-Symmetric Real Rigidity Model in BraziL

\begin{tabular}{lcccccccr}
\hline \hline Year & $\Delta y_{i}^{o}$ & $\Delta y_{i}^{*}$ & $\mu_{r}$ & $\sigma_{r}$ & $p^{R}$ & $p^{N}$ & $1-q$ & $N$ \\
\hline $1995-1996$ & 0.174 & 0.166 & 0.113 & 0.000 & 0.193 & 0.010 & 0.176 & 849,004 \\
$1996-1997$ & 0.122 & 0.088 & 0.069 & 0.000 & 0.236 & 0.029 & 0.272 & 896,797 \\
$1997-1998$ & 0.065 & 0.036 & 0.080 & 0.000 & 0.270 & 0.040 & 0.300 & 985,980 \\
$1998-1999$ & 0.078 & 0.047 & 0.045 & 0.000 & 0.184 & 0.105 & 0.255 & $1,005,791$ \\
$1999-2000$ & 0.114 & 0.111 & 0.085 & 0.029 & 0.436 & 0.132 & 0.056 & $1,042,319$ \\
2000-2001 & 0.126 & 0.107 & 0.058 & 0.001 & 0.035 & 0.484 & 0.212 & $1,085,804$ \\
2001-2002 & 0.126 & 0.122 & 0.100 & 0.009 & 0.329 & 0.124 & 0.087 & $1,199,888$ \\
\hline
\end{tabular}

Note: This table displays the mean wage changes in the observed $\left(\Delta y_{i}^{o}\right)$ and notational $\left(\Delta y_{i}^{*}\right)$ distributions, the mean of the estimated focal point of DRWR $\left(\mu_{r}\right)$ and its variance $\left(\sigma_{r}\right)$, the percentages of workers in the DRWR $\left(p^{R}\right)$ and DWNR $\left(p^{N}\right)$ regimes, the share of wage change observations observed with error $(1-q)$, and the number of observations $(N)$ for each period.

either at zero, at the rate of inflation, or at the growth rate of the minimum wage. ${ }^{19}$ Hence, there is no visual evidence of downward wage rigidities in this dataset. But before ruling out the presence of wage rigidity, we need to build, as before, a counterfactual or notional wage change distribution.

The relatively small number of wage changes in occupations (274 observations before 2002, and 304 after 2002, on average) and the limited set of covariates precludes us from applying the same methodology we used on individual data to derive a notional wage change distribution. We rely instead on Holden and Wulfsberg (2008, 2009), who build a notional wage change distribution based on observations from years when wage growth is high and, hence, unlikely to be affected by wage rigidities. In our case, the notional wage change distribution is constructed by selecting those years within the period 1981-2004 in which the median wage growth is above the seventy-fifth percentile of yearly wage growth. ${ }^{20}$

Once the notional is built, measures of rigidity at any point in the distribution can be derived by comparing the number of observed wage cuts below this point with the number of wage cuts observed in the notional. Following Holden and Wulfsberg (2008), we can define the fraction of wage cuts prevented (FWCP) by wage rigidity in point $i$ as

$$
F W C P_{t}(i)=1-q_{t}(i) / \tilde{q}_{t}(i)
$$

where $q_{t}(i)$ and $\tilde{q}_{t}(i)$ are the fractions of observed and notional wage cuts, respectively. Once the FWCP is calculated for every year, confidence intervals can be built by a simulation method that consists of repeating 1,000 times a comparison between the observed wage cuts at point $i$ with the number of wage cuts predicted by a binomial distribution that has probability $\tilde{q}_{t}(i)$ (see Holden and Wulfsberg 2008

\footnotetext{
${ }^{19}$ A possible rationale for the lack of distortions is measurement error. Survey datasets, such as PNAD, are more prone to measurement error than our administrative data. Indeed, comparisons with the RAIS data for Minas Gerais show fatter tails in the wage change distributions in PNAD, suggesting indeed greater measurement error. However, the wage change distributions in RAIS aggregated at the occupation level were also relatively smooth (see the online Appendix).

${ }^{20}$ Note that the survey is not available in 1991 and 1994 . The years selected for the construction of the notional are 1984-1985, 1986-1987, 1987-1988, 1988-1989, 1989-1990, and 1992-1993, which display an average median nominal wage growth of 1,193 percent.
} 
for details). Following our previous discussion, we concentrate on investigating the importance of downward wage rigidities at three points in the distribution: zero, the rate of inflation, and the growth rate of the minimum wage.

There are few signs of downward wage rigidities in Brazil at the occupation level. Table 6 presents our estimates of wage rigidity at the three points of the distribution aggregated across years. For the whole economy, we find that the fraction of wage cuts prevented at the rate of inflation is 0.024 . Hence, a little bit more than 2 in every 100 cuts scheduled to fall below the rate of inflation are, on average, prevented by rigidities. However, we cannot reject the null hypothesis of absence of wage rigidity at the rate of inflation $(p$-value $=0.394)$. Similarly, the FWCP is 0.006 ( $p$-value $=0.491)$ at the growth of the minimum wage, while it is 0.017 $(p$-value $=0.337)$ at zero.

We next distinguish among the wage changes of formal workers in Minas Gerais, formal workers in the whole country, and informal workers in the whole country. For each of these groups we construct a group-specific notional wage change and estimate the corresponding FWCPs. For the three groups of workers and the three cutoff points considered in the analysis, we fail to reject the null of absence of wage rigidity. Table 7 presents the FWCP and the corresponding $p$-values for each year at each of the points in the distribution considered. The message is very similar. We find weak signs of downward wage rigidity at the change of the minimum wage in only one case. In 1997-1998, the FWCP for informal workers is 0.095 with a $p$-value of 0.063 .

Robustness checks, presented in an online Appendix, yielded very similar results. First, we have experimented with an alternative methodology to derive the notional wage change distribution based on symmetry, following Lebow, Saks, and Wilson (2003); Card and Hyslop (1997); and Holden and Wulfsberg (2009). In this case, the notional in every year is built by replacing the observations below the median with the wage changes observed in the upper half of the distribution, which should not be affected by wage rigidities. Importantly, the underlying assumptions in the two approaches are orthogonal. In our preferred estimates, the identifying assumption is that the shape of the distribution is constant over time. Assuming symmetry allows for changes in shape from year to year, as long as the distribution is symmetric. A second concern with the analyses presented in this section is related to the small sample sizes within cells. When the number of individual observations we use to construct the median wage within occupations is small, changes in the composition of the workforce within cells from one year to the next might not represent true compositional changes. We derived an alternative measure of wages by occupation that is free of changes in observable characteristics. ${ }^{21}$ Again, the shape of the distributions and estimates of rigidity with these alternative series were very similar to those discussed in the text.

\footnotetext{
${ }^{21}$ This measure is obtained by first running fairly flexible yearly Mincer regressions that include a cubic polynomial in age, gender, education dummies, and a full set of interactions terms between all these variables and occupation dummies. In a second stage, we extract the occupation dummies and take first differences to construct a measure of yearly occupational wage changes that factors out changes in observable characteristics.
} 
Table 6-Downward Wage Rigidity in Occupational Data-Aggregate Estimates

\begin{tabular}{lccrr}
\hline \hline & $q_{t}(i)$ & $\tilde{q}_{t}(i)$ & FWCP & $p$-val \\
\hline Inflation rate & & & & \\
Minas Gerais & 0.48 & 0.50 & 0.04 & 0.59 \\
Formal & 0.48 & 0.47 & -0.01 & 0.87 \\
Informal & 0.48 & 0.47 & -0.02 & 0.87 \\
All workers & 0.49 & 0.51 & 0.02 & 0.39 \\
Minimum wage & & & & \\
Minas Gerais & 0.58 & 0.60 & 0.02 & 0.30 \\
Formal & 0.54 & 0.55 & -0.01 & 0.20 \\
Informal & 0.60 & 0.59 & 0.00 & 0.80 \\
All workers & 0.59 & 0.59 & & 0.49 \\
& & & -0.02 & \\
Zero wage change & & & -0.02 & 0.73 \\
Minas Gerais & 0.33 & 0.32 & -0.06 & 0.94 \\
Formal & 0.29 & 0.28 & 0.02 & 0.33 \\
Informal & 0.28 & 0.26 & & \\
All workers & 0.30 & 0.30 & & \\
\end{tabular}

Notes: The table displays the frequency of wage changes prevented (FWCP) by rigidity at the rate of inflation, the growth rate of the minimum wage, and zero. $q_{t}(i)$ and $\tilde{q}_{t}(i)$ are the incidence rates of actual and notional wage cuts, respectively, below each threshold $(i)$. The $p$-values correspond to the probability of rejecting the null hypothesis of absence of rigidity.

Table 7-Downward Wage Rigidity in Occupational Data-Yearly Estimates

\begin{tabular}{|c|c|c|c|c|}
\hline & \multicolumn{2}{|c|}{ Inflation rate } & \multicolumn{2}{|c|}{ Minimum wage } \\
\hline & FWCP & $p$-val & FWCP & $p$-val \\
\hline \multicolumn{5}{|c|}{ Minas Gerais } \\
\hline 1995-1996 & 0.19 & 0.11 & 0.02 & 0.46 \\
\hline 1996-1997 & 0.03 & 0.48 & 0.07 & 0.35 \\
\hline 1997-1998 & 0.08 & 0.28 & 0.02 & 0.41 \\
\hline 1998-1999 & 0.00 & 0.49 & -0.01 & 0.57 \\
\hline $2002-2003$ & 0.00 & 0.53 & 0.02 & 0.42 \\
\hline 2003-2004 & 0.02 & 0.50 & 0.04 & 0.39 \\
\hline \multicolumn{5}{|c|}{ Formal workers } \\
\hline 1995-1996 & -0.08 & 0.83 & -0.05 & 0.78 \\
\hline 1996-1997 & -0.01 & 0.62 & -0.01 & 0.62 \\
\hline 1997-1998 & -0.08 & 0.86 & -0.00 & 0.58 \\
\hline 1998-1999 & -0.01 & 0.66 & -0.07 & 0.89 \\
\hline 2002-2003 & 0.03 & 0.34 & 0.01 & 0.40 \\
\hline 2003-2004 & -0.01 & 0.58 & 0.00 & 0.53 \\
\hline \multicolumn{5}{|c|}{ Informal workers } \\
\hline 1995-1996 & -0.14 & 0.84 & -0.17 & 0.93 \\
\hline 1996-1997 & 0.02 & 0.46 & 0.01 & 0.48 \\
\hline 1997-1998 & 0.02 & 0.43 & 0.09 & 0.06 \\
\hline 1998-1999 & -0.07 & 0.87 & 0.05 & 0.33 \\
\hline 2002-2003 & 0.00 & 0.53 & 0.01 & 0.50 \\
\hline 2003-2004 & 0.04 & 0.33 & 0.00 & 0.53 \\
\hline
\end{tabular}

Notes: The table displays the frequency of wage changes prevented (FWCP) by rigidity at the rate of inflation and at the growth rate of the minimum wage. The $p$-values correspond to the probability of rejecting the null hypothesis of absence of rigidity. 
The apparent lack of evidence of downward wage rigidities in occupational data in Brazil suggests substantial smoothing of aggregate wages, possibly through labor turnover. Interestingly, this result contrasts with the evidence discussed by Holden and Wulfsberg $(2008,2009)$, who show that downward real and nominal wage rigidity is present in industry data from high-income countries, although the extent of rigidity observed in the macro data is lower than that found in micro studies. The large degree of labor turnover observed in developing countries may help reconcile this apparent disconnection. Since the wages of movers are typically more volatile than the wages of incumbents, ${ }^{22}$ faster labor turnover in Brazil is likely to smooth aggregate wages more than in high-income countries.

Although we do not study the impact of wage rigidity on employment and output here, the contrast between our results and previous studies suggests that the macroeconomic impact of wage rigidities in emerging countries may be more limited than in developed economies. It should be noted, though, that the wage flexibility we observe at the macro level does not necessarily imply that downward wage rigidities among incumbent workers should not have a macroeconomic impact. Firms constrained by downward wage rigidities would be forced to adapt their hiring and firing policies accordingly, a feature that hinders allocative efficiency.

\section{Conclusions}

Emerging countries have moved from high inflation regimes in the 1980 s to relatively low and stable inflation rates since the second half of the 1990s. This paper assesses how this disinflation process has shaped wage setting in two of these emerging economies: Brazil and Uruguay. The natural response of wage setters to high inflation regimes is wage indexation. This form of wage rigidity is likely to translate into inefficient allocations because relative wages are not allowed to adjust to firms' productivity developments. These efficiency losses are, in turn, likely to result in lower levels of welfare and higher unemployment. Hence, from both a macro and labor economics perspective, it is important to know how downward real wage rigidities have evolved as inflation has fallen.

Measuring downward wage rigidities at the individual level imposes serious data requirements. In this paper, we have measured the incidence and nature of wage rigidities in Brazil and Uruguay using high-quality administrative data. Although our data are less prone to measurement error than typical labor force surveys, errors in measurement may still be present. For this reason, we follow Goette, Bauer, and Sunde (2007) and estimate a model that allows for measurement error and distinguishes three types of agents: those who have flexible wages, those who resist nominal wage cuts, and those who resist real wage cuts. The model estimates the rigidity parameters by contrasting the observed individual wage changes with those of an estimated notional wage change distribution, which is the wage change that would have prevailed in the absence of wage rigidities. Importantly, we take advantage of

\footnotetext{
${ }^{22}$ See Pissarides (2010) for a review of the empirical evidence and Haefke, Sonntag, and Van Rens (2012) and Carneiro, Guimarães, and Portugal (2012) for recent applications in the United States and Portugal, respectively.
} 
the richness of our administrative datasets to estimate this notional wage change distribution year by year as a function of individual and firm characteristics.

Our analysis uncovers several important findings. First, although a nontrivial share of individuals experience wage cuts in emerging countries, there is substantial evidence of wage rigidity, either in the form of resistance to nominal wage cuts or in the form of wage indexation.

Second, the nature of wage rigidities is quite different in Brazil and Uruguay. In Brazil, wage indexation is high and stable throughout the sample period, while in Uruguay it declines rapidly. DNWR is virtually nonexistent in Brazil, but as inflation decreases it becomes very important in Uruguay, affecting more than 70 percent of the workforce by the end of the sample period. The reasons for the decline of wage indexation in Uruguay and the persistence of the same phenomenon in Brazil are consistent with the different wage-setting institutions in the two countries over the same period. While we observe a sharp decline in union coverage and a strong movement toward decentralization in wage negotiations in Uruguay, union coverage remains fairly high and stable in Brazil.

Our third finding is more nuanced and is related to the nature of wage rigidity and monetary policy. In Brazil, wage indexation is important and highly persistent throughout the sample period. However, the reference price or focal point of wage negotiations changes in coincidence with the introduction of inflation targeting by the central bank in 1999. Before inflation targeting, agents subject to DRWR resisted wage changes below changes in the minimum wage. This was probably an inherited practice of the hyperinflation years, in which inflation was highly unpredictable but the government usually adjusted the minimum wage to the changes in prices. The interesting feature is that this practice prevailed until 1999, five years after inflation stabilization. Moving away from changes in the minimum wage and centering wage negotiations around the rate of inflation required the additional credibility offered by the central bank by setting explicit targets.

When we study aggregate wages by analyzing the incidence of downward wage rigidities in observed wage changes in different occupations, we find little sign of wage rigidity in Brazil. This suggests that compositional effects and market forces associated with labor and firm turnover smooth out downward wage rigidities among incumbent workers observed at the individual level. The corollary is that the macroeconomic impact of the substantial degree of downward wage rigidities that we document here, either in terms of employment or output, might not be as large as expected—an issue that deserves further research.

\section{REFERENCES}

-Aitkin, Murray. 1987. "Modelling Variance Heterogeneity in Normal Regression Using GLIM." Applied Statistics 36 (3): 332-39.

Altonji, Joseph G., and Paul J. Devereux. 2000. "The extent and consequences of downward nominal wage rigidity." In Research in Labor Economics: Worker Well-Being, Vol. 19, edited by Solomon W. Polachek, 383-431. Amsterdam: Elsevier.

Arbache, Jorge Saba. 2002. "Unions and the Labor Market in Brazil," In IPEA-World Bank Brazil Jobs Report, 61-95, edited by the World Bank. Washington, DC. 
Babecký, Jan, Philip Du Caju, Theodora Kosma, Martina Lawless, Julián Messina, and Tairi Rõõm. 2012. "How do European firms adjust their labour costs when nominal wages are rigid?" Labour Economics 19 (5): 792-801.

Barwell, Richard D., and Mark E. Schweitzer. 2007. "The Incidence of Nominal and Real Wage Rigidities in Great Britain: 1978-98.” Economic Journal 117 (524): F553-69.

Bauer, Thomas, Holger Bonin, Lorenz Goette, and Uwe Sunde. 2007. "Real and Nominal Wage Rigidities and the Rate of Inflation: Evidence from West German Micro Data." Economic Journal 117 (518): F508-29.

-Benati, Luca. 2008. “Investigating Inflation Persistence Across Monetary Regimes.” Quarterly Journal of Economics 123 (3): 1005-60.

Bernanke, Ben S. 2004. “The Great Moderation.” Speech, Eastern Economic Association, Washington, DC, February 20. http://www.federalreserve.gov/boarddocs/speeches/2004/20040220/.

Bewley, Truman F. 1999. Why Wages Don't Fall During A Recession. Cambridge, MA: Harvard University Press.

Campbell, Carl M., III, and Kunal S. Kamlani. 1997. "The Reasons for Wage Rigidity: Evidence from a Survey of Firms." Quarterly Journal of Economics 112 (3): 759-89.

Card, David, and Dean Hyslop. 1997. “Does Inflation 'Grease the Wheels of the Labor Market'?” In Reducing Inflation: Motivation and Strategy, edited by Christina D. Romer and David H. Romer, 71-122. Chicago: University of Chicago Press.

Carneiro, Anabela, Paulo Guimarães, and Pedro Portugal. 2012. "Real Wages and the Business Cycle: Accounting for Worker, Firm, and Job Title Heterogeneity." American Economic Journal: Macroeconomics 4 (2): 133-52.

Cassoni, Adriana, Gaston J. Labadie, and Gabriela Fachola. 2002. "The Economic Effects of Unions in Latin America: Their Impact on Wages and the Economic Performance of Firms in Uruguay." Inter-American Development Bank Research Network Working Paper 466.

Castellanos, Sara G., Rodrigo García-Verdú, and David S. Kaplan. 2004. "Nominal wage rigidities in Mexico: evidence from social security records.” Journal of Development Economics 75 (2): 507-33.

Devicienti, Francesco, Aagata Maida, and Paolo Sestito. 2007. "Downward Wage Rigidity in Italy: Micro-Based Measures and Implications.” Economic Journal 117 (524): F530-52.

Dickens, William T., Lorenz Goette, Erica Groshen, Steinar Holden, Julian Messina, Mark E. Schweitzer, Jarkko Turunen, and Melanie E. Ward. 2007. "How Wages Change: Micro Evidence from the International Wage Flexibility Project." Journal of Economic Perspectives 21 (2): 195-214.

Goette, Lorenz, Thomas Bauer, and Uwe Sunde. 2007. "Wage Rigidity: Measurement, Causes and Consequences.” Economic Journal 117 (524): F499-507.

-Gottschalk, Peter. 2005. "Downward Nominal-Wage Flexibility: Real or Measurement Error." Review of Economics and Statistics 87 (3): 556-68.

Haefke, Christian, Marcus Sonntag, and Thijs Van Rens. 2012. "Wage Rigidity and Job Creation." Centre for Economic Policy Research (CEPR) Discussion Paper 8968.

Haltiwanger, John, Stefano Scarpetta, and Helena Schweiger. 2010. "Cross country differences in job reallocation: the role of industry, firm size and regulations." European Bank for Reconstruction and Development Working Paper 116.

-Harding, Don, and Adrian Pagan. 2002. "Dissecting the cycle: a methodological investigation." Journal of Monetary Economics 49 (2): 365-81.

Hofmann, Boris, Gert Peersman, and Roland Straub. 2010. "Time variation in U.S. wage dynamics." European Central Bank (ECB) Working Paper 1230.

Holden, Steinar, and Fredrik Wulfsberg. 2008. "Downward Nominal Wage Rigidity in the OECD." B. E. Journal of Macroeconomics: Advances in Macroeconomics 8 (1): Article 1.

Holden, Steinar, and Fredrik Wulfsberg. 2009. "How strong is the macroeconomic case for downward real wage rigidity?" Journal of Monetary Economics 56 (4): 605-15.

Kahn, Shulamit. 1997. "Evidence of Nominal Wage Stickiness from Microdata." American Economic Review 87 (5): 993-1008.

Kahneman, Daniel, Jack L. Knetsch, and Richard H. Thaler. 1986. "Fairness as a Constraint on Profit Seeking: Entitlement in the Market.” American Economic Review 76 (4): 728-41.

Kahneman, Daniel, and Amos Tversky. 1979. "Prospect Theory: An Analysis of Decision under Risk." Econometrica 47 (2): 263-92.

Lebow, David E., Raven E. Saks, and Beth Anne Wilson. 2003. "Downward Nominal Wage Rigidity: Evidence from the Employment Cost Index." B. E. Journal of Macroeconomics: Advances in Macroeconomics 3 (1): Article 2.

Lemos, Sara. 2006. "Anticipated effects of the minimum wage on prices." Applied Economics 38 (3): 325-37. 
Maloney, William F., and Jairo Nuño Mendez. 2004. "Measuring the Impact of Minimum Wages: Evidence from Latin America." In Law and Employment: Lessons from Latin American and the Caribbean, edited by James J. Heckman and Carmen Pagés, 109-30. Chicago: University of Chicago Press.

-Messina, Julián, and Anna Sanz-de-Galdeano. 2014. "Wage Rigidity and Disinflation in Emerging Countries: Dataset." American Economic Journal: Macroeconomics. http://dx.doi.org/10.1257/ mac.6.1.102.

Perry, Guillermo E., William F. Maloney, Omar S. Arias, Pablo Fajnzylber, Andrew D. Mason, and Jaime Saavedra-Chanduvi. 2007. Informality: Exit and Exclusion. Washington, DC: World Bank.

Pissarides, Christopher A. 2010. "The Unemployment Volatility Puzzle: Is Wage Stickiness the Answer?" Econometrica 77 (5): 1339-69.

Senatore Camerota, Luis Alberto. 2007. "Los cambios institucionales y normativos de la política laboral y su impacto sobre el sujeto sindical: el caso de Uruguay en el período 2005-2007.” http:// www.uel.br/grupo-pesquisa/gepal/terceirosimposio/luizalberto.pdf (accessed November 16, 2011).

-Smith, Jennifer C. 2000. "Nominal Wage Rigidity in the United Kingdom." Economic Journal 110 (462): 176-95.

Zunino, Mauricio. 2009. "Impactos de la Reinstauración de Los Consejos de Salarios sobre la Distribución Salarial en Uruguay: conclusiones, hipótesis e interrogantes." Centro de Estudios Distributivos, Laborales y Sociales Working Paper 92. 